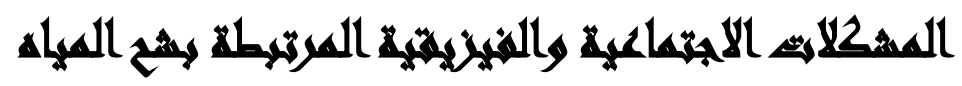

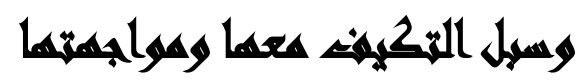

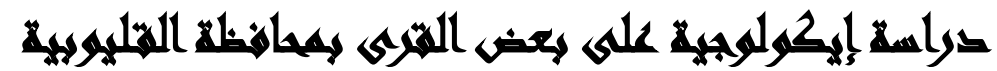

[9]

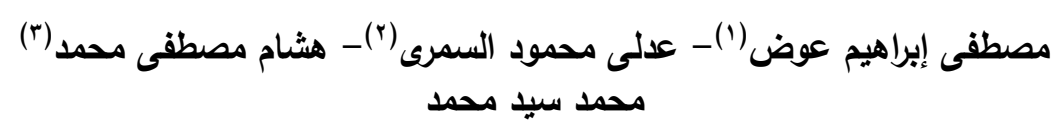

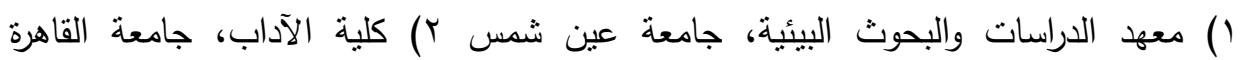

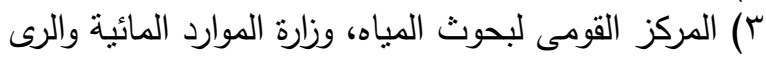

\section{المستحلصن}

تهدف هذه الدراسة بصفة رئيسية إلى التعرف على شح المياه والأسباب المؤدية إليه،

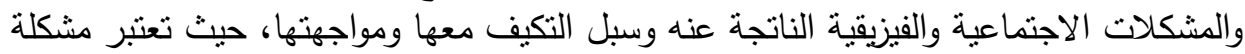
شح المياه من أخطر الأزمات التي تهدد مستقبل البشرية في الفترة الحالية. حيث تم وضع وفع وفئه تساؤلات لمعرفة علاقة شح المياه وأسبابه ببعض المتغيرات وذلك للتوصل إلى رؤية مستقبلية لمواجهة مشكلات شتح المياه. ولتحقيق الدراسة نم تطبيق بعض النظريات الخاصة بالدراسة منها نظرية النسبق

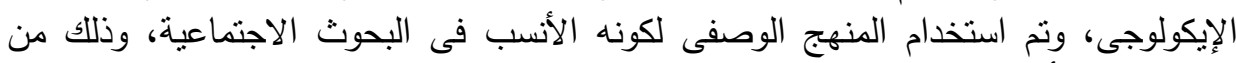
خلال وصف أسباب شتح المياه والآثار المترتبة عليه وكيفية تعامل المزارعين معه، وتم استخدام

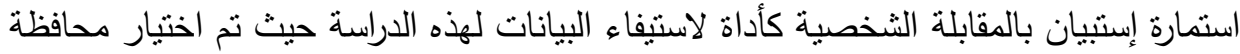

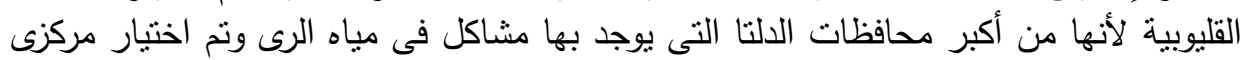

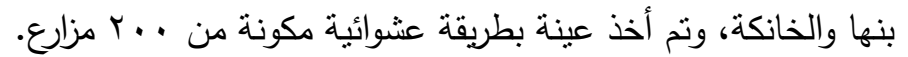
وخلصت هذه الاراسة إلى كثير من التتائج كان أهمها:

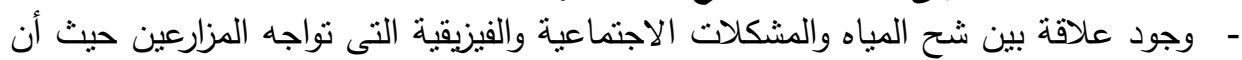

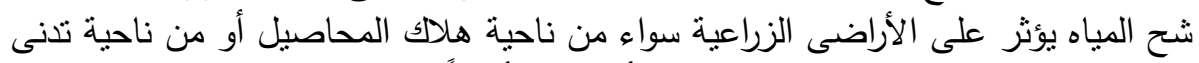

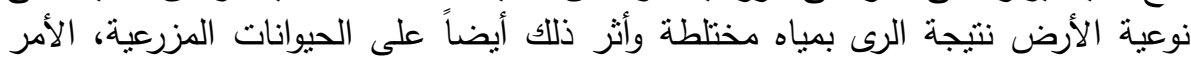
الذى يؤدى إلى تدهور الحالة الاقتصادية للمزارعين. - ـ إلقاء المخلفات (حيوانات نافقة وخلافه) يؤدى إلى تلى تلوث المياه مما بتسبب فئ إهدار كمية من المياه النقية. 


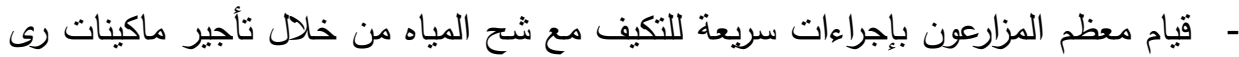

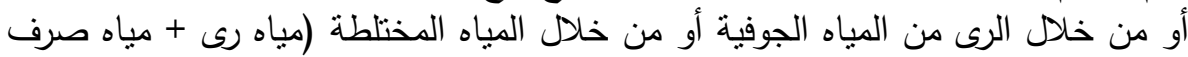

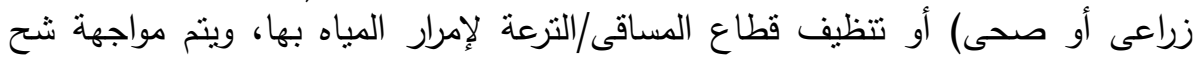
المياه عن طريق عمل محاضر تبديد مياه للمخالفين وذللك للحد من إهدار الإل المياه. وكاتت أهم التوصيات:

- عمل دورات تدريبية لرفع المستوى التقافى والمعرفى والسلوكى للمزارعين للتوعية بأهمية

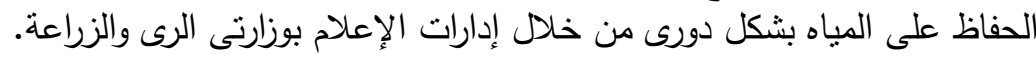

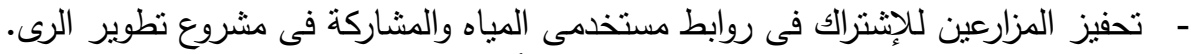

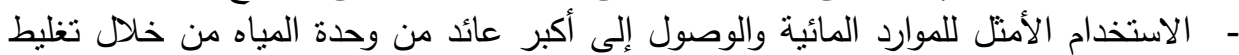

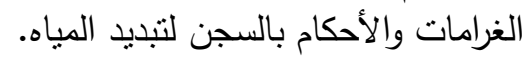

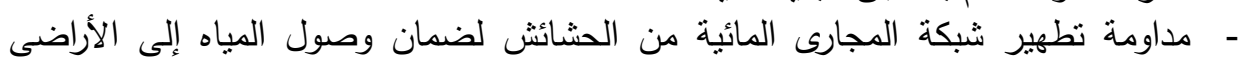

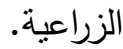

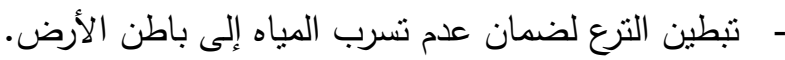

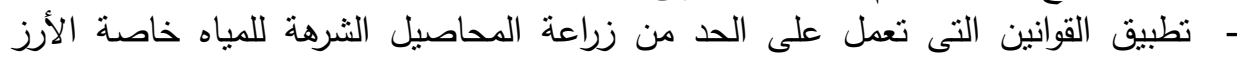
والعمل على الاستفادة من تجارة المياه الافتراضية. - - إلزام المزارعين باستخدام طرق الرى المطور (رى بالرش - التتقيط) للحفاظ على نقطة المياه.

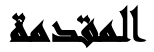

يمثل الماء عصب الحياة على سطح كوكب الأرض وبدونه تتعدم كل صور الحياة النباتية والحيوانية والآدمية. وفى البلاد الواقعة فى نطاق المناطق الجافة وشبه الجافة ( ومنها جمهورية مصر العربية ) يقل أو ينعدم معدل سقوط الأمطار وعليه يعتمد الإنسان على مياه الأنهار.

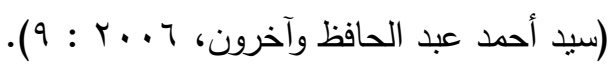
وقد تجمع الناس منذ بدء الخليقة حول مصادر المياه، والحضارات القديمة قامت على

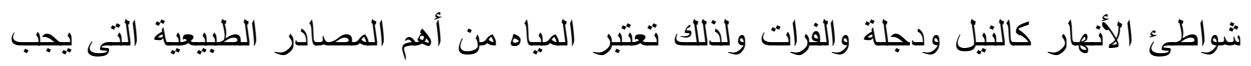

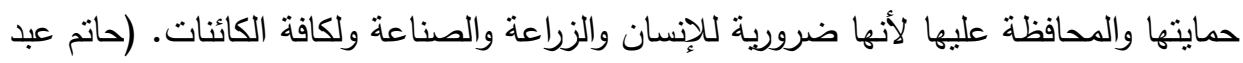

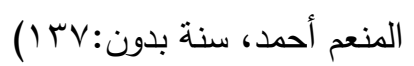


وخلال السنوات العشرين الماضية وُضحَ العديد من المؤشرات والمقاييس لتقييم كمية الموارد المائية مثل ندرة المياه أو الإجهاد المائى، وكان هناك صعوبة فئ وصنئ التمييز بين حالات المياه، حيث هنالك جوانب كثيرة لها نأثير على المياه، ولكن تم وضع مؤشرات أولية لتقييم ندرة المياه

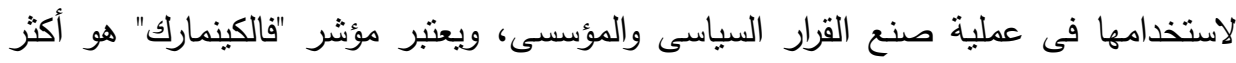
المقاييس استخداماً على نطاق واسع حيث يعرف الإجهاد المائى على أنه "جزء من مجموع لئه

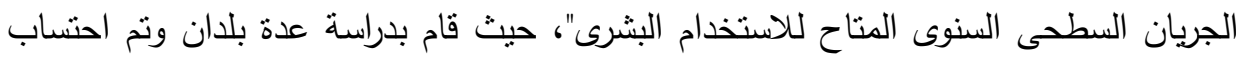
استهلاك المباه للفرد، وأوضاع المياه في أى مكان وتصنيفها على النحو التالي: وفرة مياه، قلة مياه، شح مياه، والندرة المطلقة. ويشكل الثح المتتامى للمياه والتتافس عليها تهديداً جسيماً تفرضها التطورات المستقبلية على نحو يؤثر فى مساعى تحقيق الأمن الغذائى والحد من الفقر على مستوى إقليم الثرق لهن

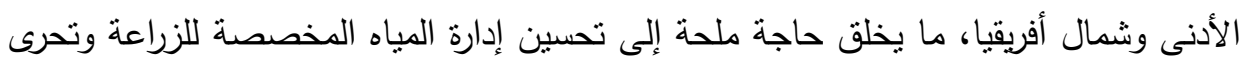
الممارسات الفضلى والحلول الناجحة فى بلدان هذا الإقليم التى تعد لازمة لاستخدام موارد المياه إنهاه

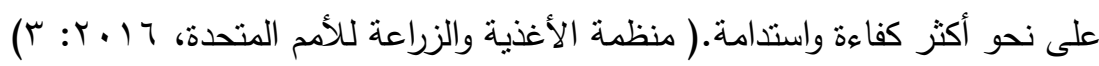

\section{and I2an}

تدخل مصر منطقة شح المياه وفقاً لما نشره تقرير "الثورة الزرقاء: الماء في العالم"، لدول العالم التي تعاني من مشكلات المباه، والذى تضمن الدول العربية التي تعاني شّح المباه، ومنها لهاه

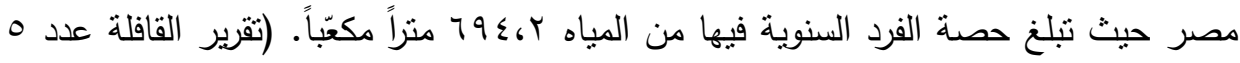

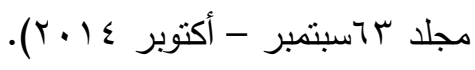

كما نوضح بعض الدراسات السابقة أن هناك مشاكل فى المياه فى مصر ومنها دراسة

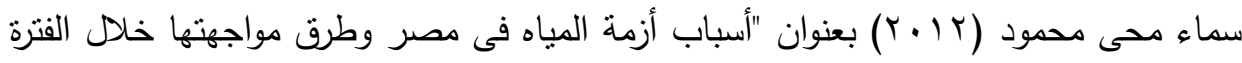

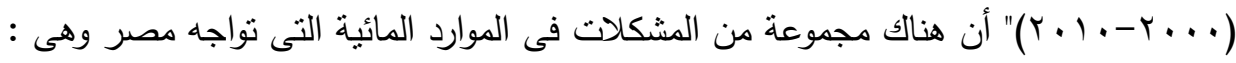

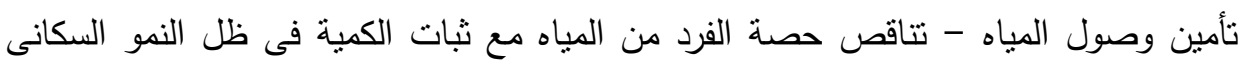

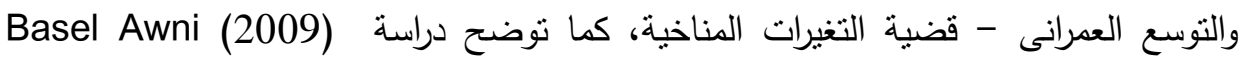

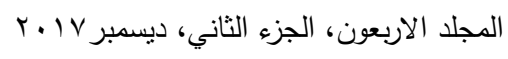


بعنوان: إدارة المياه والتربة تحت إستخدام المياه العادمة المعالجة، حيث تطرقت إلى أن النقص الحادث فى المياه المطلوبة للزراعة جعل أنه لابد حتماً من استخدام مصادر أخداه أخرى.

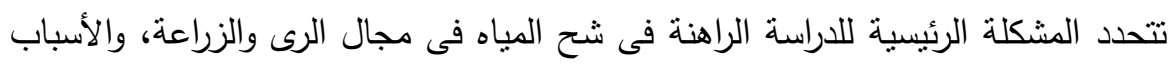

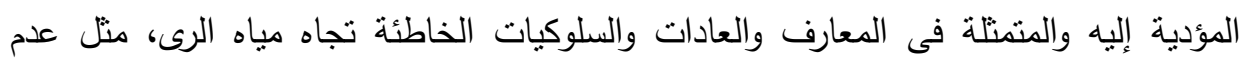
ترشيد استهالاك المباه وتلويث المياه بالمبيدات والأسمدة وإلقاء المخلفات بالتزع، وتأثثر البيئة ولئة الفيزيقية كضعف البينة التحتية وتأثير المناخ حيث تؤدى درجات الحرارة المرتفعة إلى فقد كمبات كبيرة من المياه عن طريق البخر • والآثار والمشكلات الاجتماعية والفيزيقية الناتجة عن حدوث

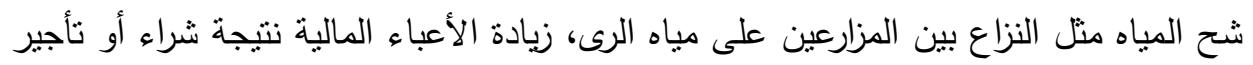

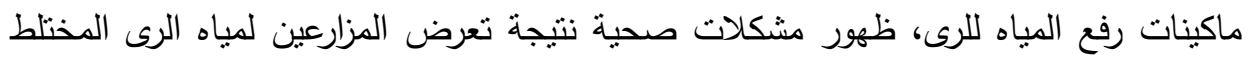
بمياه الصرف غير المعالج بأنواعه، انتشار الحشرات والقوارض والثعابين نتيجة عدم رفع ناتج تطهير الترع والمصارف من على جوانبها، خسارة المزارعين نتيجة هلاك المحاصيل الزراعية لضعف أو عدم وصول المياه للزراعات، بوار الأراضى الزراعية نتيجة عدم وصول المياه إليها.

\section{تماولاهيت المهيد}

تسعى الدراسة للإجابة على تساؤلات تعبر عن المشكلة البحثية وتتمنل فى: ا ـ ما مدى وجود علاقة بين معارف ووعى وسلوكيات المزارعين وشح المياه؟

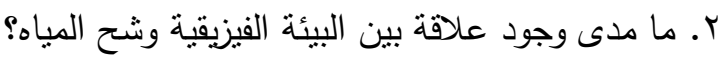

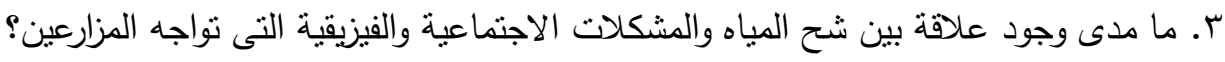

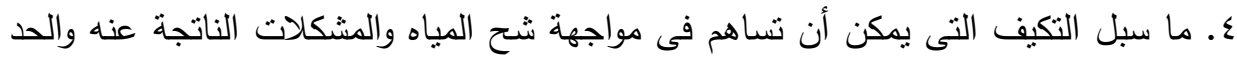




\section{أهمية الهبهش}

تكمن الأهية النظرية للاراسة فى الاستفادة من التراث النظرى لجميع الدراسات والأبحاث المكتوبة كونها نسعى لتناول مشكلة شح المياه فى مجال الزراعة والتى تعد أهم أسباب الحياة

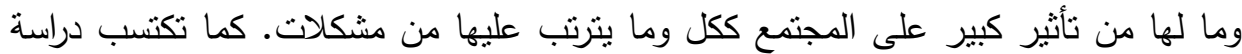
المشكلات المترتبة على شح المياه أهمية خاصة بالنظر إلى الاحتياجات المائية المتزايدة للزراعة فى مصر ومشكلة نوفير المياه الضرورية للتوسع الزراعى لمواجهة الأعداد المتزايدة من الهنه السكان والحفاظ على الأمن الغذائى.

تكمن الأهمية التطبيقية للاراسة فى الوقوف على على الأسباب التى تنؤدى إلى شح المياه

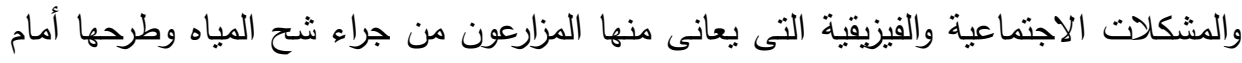

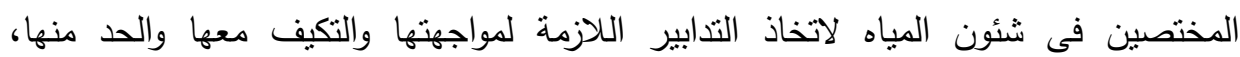
والاستفادة من نتائج الدراسة التى تمكن المسئولين بالجهات المختصة من التخطيط العلمى لانى

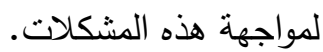

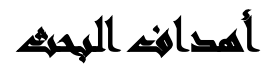

يهدف البحث إلى التعرف على شح المياه وآثاره على مجال الزراعة والأسباب المؤدية إليه، والمشكلات الاجتماعية والفيزيقية المرتبطة به نتيجة للاختلال المتصاعد فى المنظومة الإيكولوجية والضغوط البيئية والتى قد يترتب عليها إعاقة جهود التتمية المستدامة، ومحاولة التوصل إلى رؤية مستقلية لكيفية إدارة الموارد المائية فى ظل المتغيرات والمستجدات الإقليمية والدولية للوفاء بالاحتباجات المائية المصرية للأغراض الزرايه النهاعية. وسوف يتم ذلك من خلال عدد من الأهداف الفرعية وهى كالتالى:

$$
\text { ( ) التعرف على الأسباب المؤدية إلى شح المئ المياه. }
$$

r) الكثف عن المشكلات الاجتماعية والفيزيقية الناتجة عن شح المياه المياه. r) الوصول إلى مفترحات للتكيف ومواجهة شح المياه والمشكلات الاجتماعية والفيزيقية المترتبة 


\section{هورو المهنه}

1-حدود مجالية: وصف مجتمع الدراسة وخصائصه والمؤثرات الاجتماعية والدراسات السابقة فى هذا الثأن واكتشاف العلاقة بين شح المياه والمشكلات الاجتماعية والفيزيقية للمزارعين.

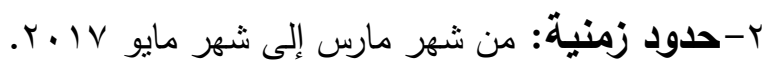
r-حدود مكانية: مركزى (بنها - الخانكة) بمحافظة القليوبية.

\section{هنهمج الهيهم}

اعتمدت الدراسة على المنهج الوصفى التحليلى لوصف ظاهرة شح المياه وتقسير ظهورها،

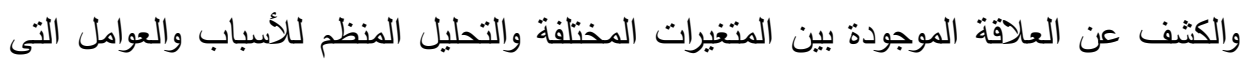
تتحكم فى مشكلة الدراسة وذلك من خلال عرض البيانات والمعلومات المتاحة عن الموارد المائية واستخداماتها بالنسبة للزراعة فى مصر حالياً ومستقبلاً، للوصول إلى بعض ودن النتائج والاستتناجات التى تسهم فى معالجة موضوع الدراسة وتقديم الحلول اللازمة له.

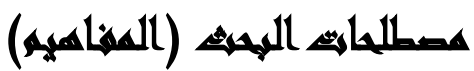

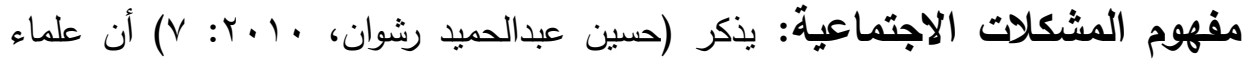
الاجتماع عرفوا المشكلات الاجتماعية بأنها "مواقف معينة تستوجب التصحيح أو ظروف معينة لها تأثيراتها فى الناس بحيث يخشى المجتمع على تهديد كيانه أو نظمه منها، والمشكلات

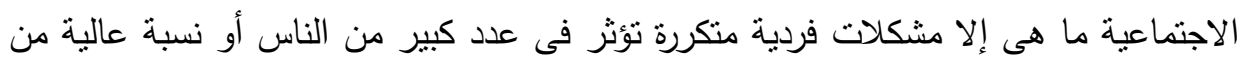
المجتمع.

التعريف الإجرائى للمشكلات الاجتماعية: هى المشكلات التى نواجه المزارعين، نتيجة نقص وتلوث المياه، مما تعجز فيه قدراتهم على مواجنها، وما يستلزم ذللك من مشاركة جماعية ومجتمعية لإيجاد الحلول لهذه المشكلات للتكيف معها ومواجهتها. 
مفهوم المشكلات الفيزيقية: يقصد بالبيئة الفيزيقية ذلك المكان الذى يعيش فى إطاره الفرد، وبناءً على ذلك فإن البيئة بمعناها الواسع هى الحى أو المنطقة أو المدينة السكنية لما لها من

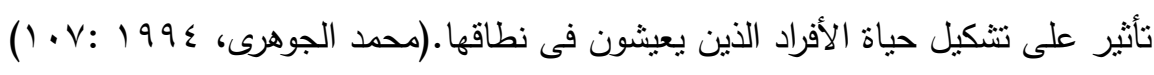

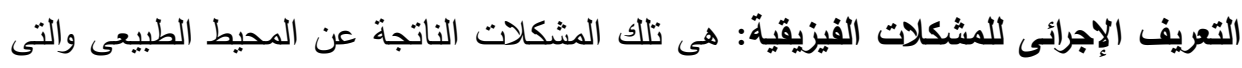
تؤثز على المياه ومن ثم المزارعين، وتؤدى إلى تدهور الأراضى الزراعية من جراء نقص لتص وتلوث

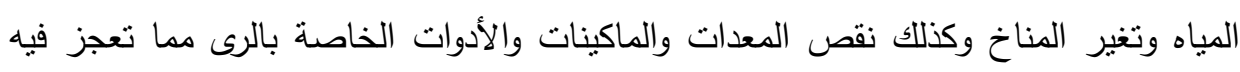

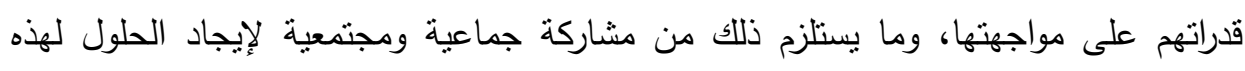
المشكلات للتكيف معها ومواجهنها. مفهوم شَح المياه: نشير موسوعة (wikipedia) إلى أن شح المياه هو مصطلح يشير إلى

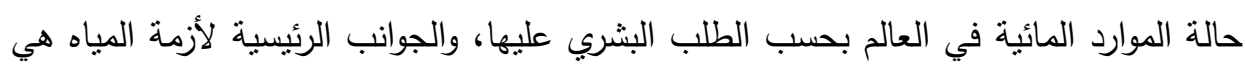

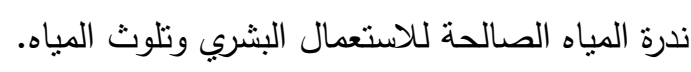

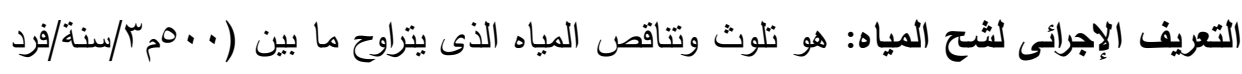

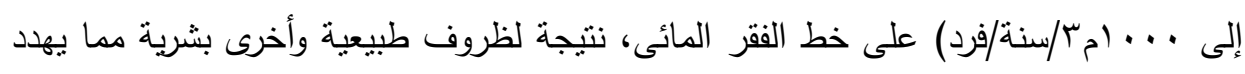

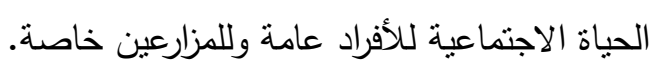
مفهوم التكيف والمواجهة: يشير قاموس علم الاجنماع إلى التكيف بأنه مصطلح أستعير من البيولوجيا حيث يشير إلى توافق الكائن العضوى مع بيئته، وفى أثثاء عملية التكيف الناتجة

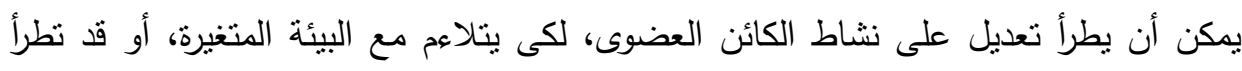
تغيرات أساسية على الكائن العضوى تسهم فى بقاء النوع. ولهذا عندما استخدم استخداماً اجنماعياً ظل يحمل معنى التوافق أو التلاؤم. (محمد عاطف غيث: التعريف الإجرائى للتكيف والمواجهة: هو محاولة المزارعين لضبط المطالب والصراعات مع التصات نقص وتلوث المياه التى ترهق مصادر تكيفهم، أى أنه يتضدن جهود المزارعين لضبط البيئات

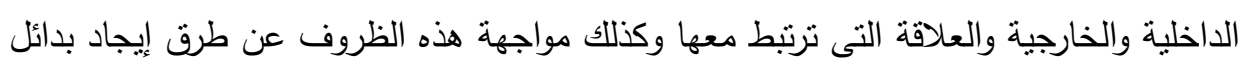
وحلول لها. 


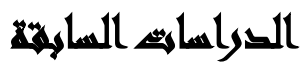

تم عرض البحوث والدراسات العلمية ذات العلاقة المباشرة وغير المباشرة بموضوع الدراسة والتى ترتبط بمشكلات المياه بشكل عام وبشح المياه بوجه خاص، وبيان أوجه الاتفاق

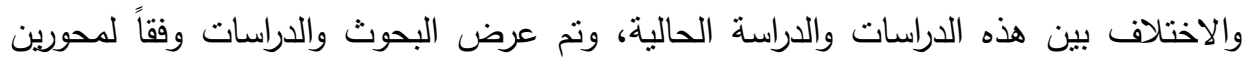
رئيسيين هما:

$$
\text { المحور الأول : دراسات تتاولت الأسباب المختلفة لمشكلات المباه. }
$$

المحور الثانى: دراسات تتاولت المتغيرات المختلفة لمواجهة مشكلات وتحديات المياه. دراسة أمل السيد إسماعيل السيد(0 ب ب) "استهلاك المياه فى المجتمعات الخضراء

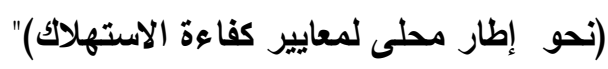
تهاف الاراسة إلى "تطوير إطار محلى لتحقيق كفاءة استخدام المياه من منظور

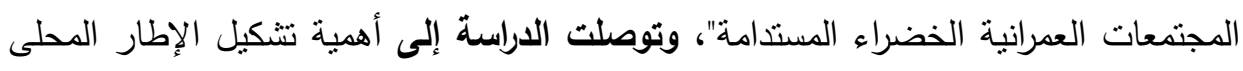

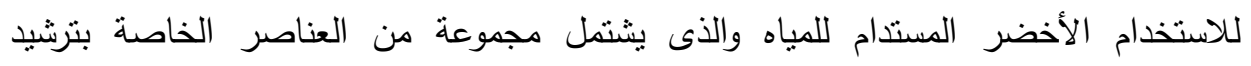

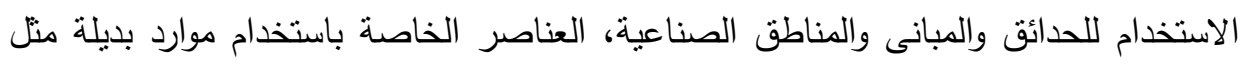

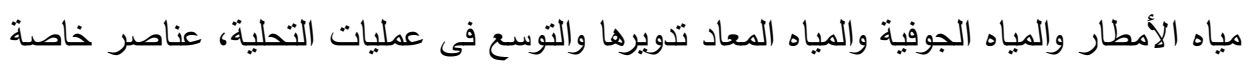
بجودة المباه. دراسة مرفت محمد عبد الوهاب(10 ب ب) " المياه الافتراضية كأداة لتحقيق الأمن

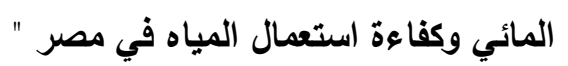
تسعى الاراسة لعرض العديد من التحديات التى تواجه مصر وتتعلق بمواردها المائية فهى وهي تواجه مفاوضات ضاربة حول مياه النيل فيما يتعلق بقضية "سد النهضة" الاثيوبى وتأثير حصنها البالغة 0،000 مليار منز مكعب سنويا، بالإضافة إلى نزايد النمو السكاني، والتغيرات

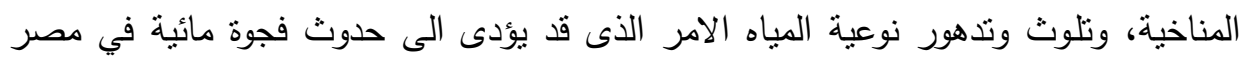

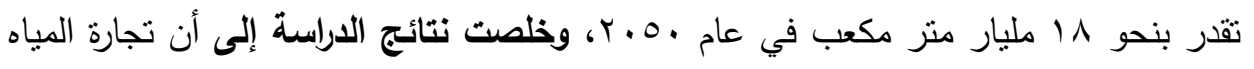
الافتراضية أمر واقع في مصر، ولكن لم يتم أخذها في الاعنبار في سياسات تخطيط وإدارة 
الموارد المائية بعد، حيث يجب إدخال قيمة المياه الافتراضية للمنتجات ضمن حسابات التكاليف

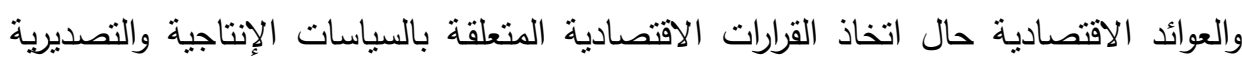
والاستيرادية، وضرورة توعية المزارعين بمدى ندرة إمدادات المياه بمصر وذلك لضمان أن ينت

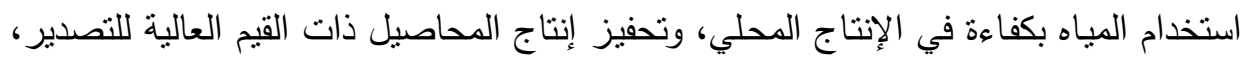
والحد من المساحة المزروعة بالمحاصيل ذات الاستخدام الكثيف للمياه، كما من المهم خلق القاه وعي بيئي لدى الأفراد للانتفاع بالمياه، حيث إن معرفة المياه الافتراضية لمختلف السلع والخدمات يخلق وعيا لدى الأفراد بالأثر البيئي لاستهلاكهم هذه السلع والخدمات. دراسة Lilah Zautner (2011) تحت عنوان تقييم مقارن تعرض نظام المياه في المجتمع لندرة المياه في بوكي وكييف كريك بأريزونا تستهذف الدراسة تقييم شامل لمشكلة عدم التأمين لندرة الموارد المياه بالتركيز على بارئل العوامل الفيزيائية-الحيوية والاجتماعية والمؤسسية التي تؤثر على ضعف نظم المياه في تهي

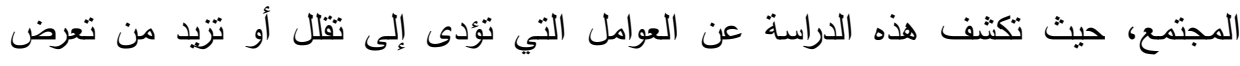

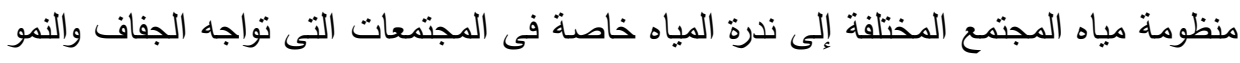

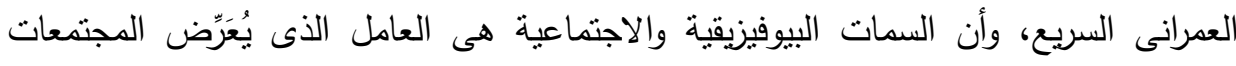
لمخاطر منل الجفاف وتغير المناخ طويل المدى.

وتوصلت الاراسة إلى أن السمات الصخرية لطبقات الأرض هى أحد العوامل البيوفيزيقية

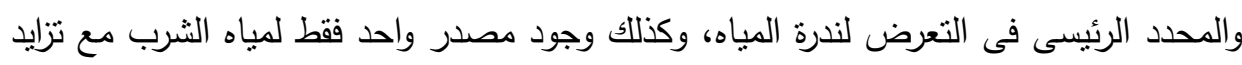
عدد السكان يزيد من مشكلة ندرة المياه.

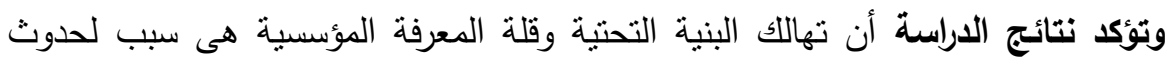

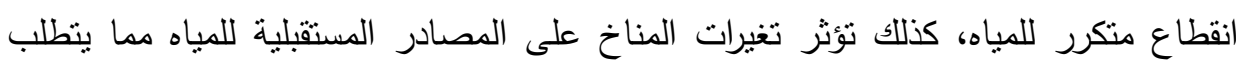

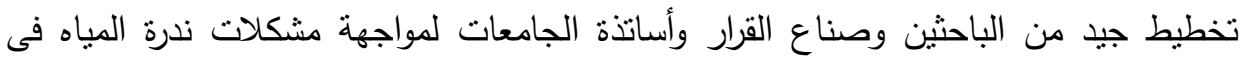
المستقبل. 
دراسة Yong Xia CaI (2009) تحت عنوان المياه، تغيرات المناخ، وجودة (نوعية) المياه: ثلاث مقالات اقتصادي

استهرفت الدراسة مناقشة ثلاث قضايا خاصة بالمياه فى المستقبل. حيث يركز المقال

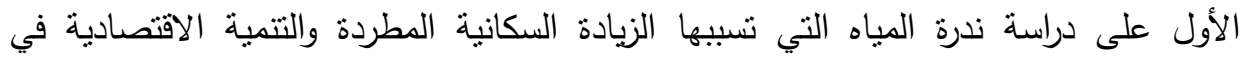
تكساس، والمقال الثاني يدرس ندرة المياه من خلال سيناريو تغير المناخ في تكساس، بينما يناقش المقال الثالث جودة المياه المرنبطة بالزرنيخ في مياه الثرب. لئرياه أوضحت النتائج أن بعض المدن والمقاطعات لديها كم مياه كافي، بينما نواجه مقاطعات لترنيات ومدن مثل ( دالاس- فورت نورث- وأوستن) مشكلات تتعلق بندرة المياه.

وفي دراسة أثر تغير المناخ تم استخلاص النتائج من خلال سيناريو الانبعاثات، فوجد أن ولاية تكساس من الولايات التي لا زال لديها وفرة في المياه وسوف تبدأ في مواجهة مشاكل المياه

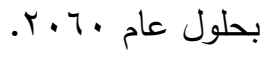
في المقال الثالث، تم تطوير نموذج هيكلي ثنائي المرحلة إلى نموذج محلي لتعديل السلوكيات الخاطئة والتركيز على مخاطر حدوث وفيات مرتبطة بوجود الزرنيخ في مياه الشرب.

\section{الإطالم المنهبs اللهas}

أولاً: منهج الدراسة: اعتمدت الدراسة على المنهج الوصفى، من أجل وصف الظاهرة فى وضعها الراهن وتحليلها. ثانياً: الطريقة العامة للبحث: إعتمدت الدراسة الحالية على طريقة المسح الاجنماعى عن طريق العينة لجمع معلومات وبيانات حول المشكلات الاجتماعية والفيزيقية المرتبة بشح المياه، للوصول إلى كيفية التكيف ومواجهة هذه المشكلات ومن ثم تعميمها. ثالثاً: أدوات جمع البيانات: اعتمدت هذه الدراسة فى جمع البيانات الميدانية على استخدام استمارة استنيان، قام الباحث بإعدادها كأداة لإجراء الدراسة الميدانية، واشتملت إستمارة الاستبيان

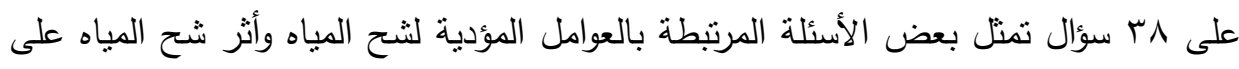


المزارعين وكيفية التكيف ومواجهة هذه الظاهرة، إعتمد الباحث على تحديد صدق إستمارة الإسنبيان على الصدق الظاهرى (صدق المحكمين)، وقام الباحث بتتفيذ ملاحظات الدحكمين وصولا للصورة النهائية للإستمارة الاستبيان. وتم تقسيم استمارة الإستبيان إلى (•) محاور كالتى: المحور الأول: المستوى المعرفى والثقافى للمزارعين بالوضع المائى فى مصر وأثنره على شح إلى المياه. المحور الثانى: سلوكيات واتجاهات المزارعين نحو الرى فى مصر وأثثر على شح المياه. المحور الثالث: أثر البيئة الطبيعية (الفيزيقية) على شح المياته المحور الرابيع: أثز شح المياه على المزارعين والأراضى الزراعية. المحور الخامس: سبل التكيف ومواجهة شح المياه والمشكلات الناتجة عنه والحد منهاه تم حساب الثبات بتطبيق إستمارة الاستبيان وإعادة التطبيق لعينة مكونة من (• ( ) مزارعين بفارق زمنى من ( • إلى ع ( ) يوم على نفس العينة وبلغ معامل الثبات (9 ( • ). رابعاً: مجتمع الدراسة: تمثل مجتمع الدراسة فى المزارعين من مركزى بنها والخانكة بمحافظة القليوبية.

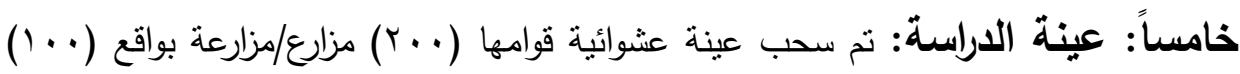
عينة من مركز بنها و (. . (1) عينة من مركز الخانكة.

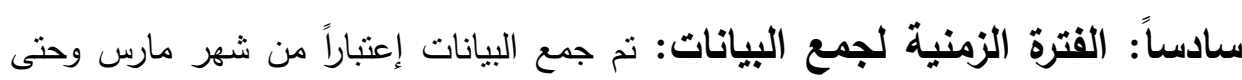

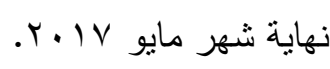
سابعاً: أساليب التحليل والتفسير: اعتمدت الدراسة على إسلوب التحليل الكمى، حيث نم التعبير عن النتائج بصورة إحصائية. 


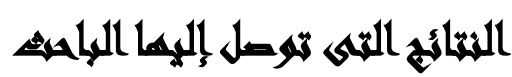

توصل الباحث إلى نتائج الدراسة من خلال توضيح العلاقة بين المتغيرات وذلك بتقسيم محاور الاستبيان على ثلاثة فصول: الفصل الرابع تحت عنوان: المظاهر المعرفية والسلوكية للمزارعين بالوضع المائى فى مصر وأثثره على شح المياه، من خلال محورين: المحور الأول: المستوى المعرفى والثقافى للمزارعين بالوضع المائى فى مصر وأثثره على شح

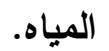

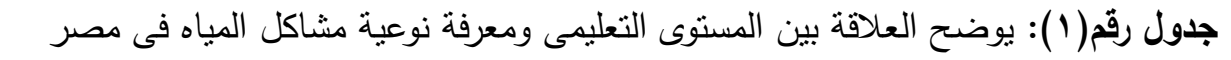

\begin{tabular}{|c|c|c|c|c|c|c|c|}
\hline النسبة & أجمالى & ئة في كمية & مشا & هُ فئ كمية & مشاء & الحالة التعليمية & \\
\hline$\%$ & S & $\%$ & ك & $\%$ & ك & & \\
\hline$\%$ \%r & $7 \varepsilon$ & $\begin{array}{c}\% \text { \%) } \\
\% r, 1 r\end{array}$ & r & $\begin{array}{c}\% r \mid \\
\% 97, \wedge \wedge\end{array}$ & TY & أمى & 1 \\
\hline \%тч & VY & $\begin{array}{c}\% \vee \\
\% \backslash 9, \leq \varepsilon\end{array}$ & $1 \leqslant$ & $\begin{array}{c}\% r q \\
\% \wedge \cdot, 07\end{array}$ & 01 & يقرأ ويكتب & $r$ \\
\hline$\% 0$ & 1. & $\begin{array}{c}\% 1 \\
\% r .\end{array}$ & r & $\begin{array}{l}\% \varepsilon \\
\% \wedge\end{array}$ & $\wedge$ & حاصل علي شهادة الابئية & $\Gamma$ \\
\hline$\% \uparrow, 0$ & 14 & $\begin{array}{c}\% r \\
\% r \cdot, V \vee\end{array}$ & $\varepsilon$ & $\begin{array}{c}\% \leqslant, 0 \\
\% 79, \text { r }\end{array}$ & 9 & حاصل على الإعدادية & $\varepsilon$ \\
\hline$\%$ & rT & $\begin{array}{c}\% 1 \cdot \\
\% \vee 7,94\end{array}$ & $r$. & $\begin{array}{c}\% r \\
\% r r, \cdot \wedge\end{array}$ & 7 & حاصل على الثانوية أو & 0 \\
\hline$\%$ & $\wedge$ & $\begin{array}{l}\% \curlyvee, 0 \\
\% \wedge \vee, 0\end{array}$ & V & $\begin{array}{l}\% \cdot, 0 \\
\% \backslash r, 0\end{array}$ & 1 & حاصل على مؤهل فوق & 7 \\
\hline$\%$ \%,० & V & $\begin{array}{l}\% r, 0 \\
\% 1 \ldots\end{array}$ & V & $\%$. & . & حاصل على مؤهل جامعى & V \\
\hline$\% 1 \ldots$ & r.. & $\%$ \% & 07 & $\% \vee r$ & $1 \leq \varepsilon$ & الإجمالي & \\
\hline
\end{tabular}

الجدول السابق يوضح بصورة إجمالية أن معرفة مشاكل المياه فى الكمية فقط إحتلت المرتبة الأولى بين مفردات العينة بنسبة \&r\%. وجاء فى المرتبة الثانبة معرفة أن مشاكل المباه

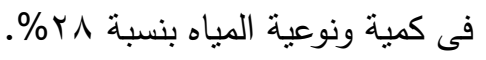


جدول رقم(ץ): يوضح العلاقة بين الحيازة الزراعية وادرالك أن مناوبات الرى مفيدة أم لا:

\begin{tabular}{|c|c|c|c|c|c|c|c|}
\hline النسبة & أجكمارلى & \multicolumn{2}{|l|}{ ע } & \multicolumn{2}{|c|}{ 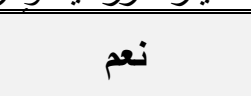 } & \multirow{2}{*}{ الحيازة المزرعية } & \multirow{2}{*}{ r } \\
\hline$\%$ & S & $\%$ & ك5 & $\%$ & ك & & \\
\hline$\%$ \%V & $1 \pi \varepsilon$ & $\begin{array}{c}\% \wedge, 0 \\
\% \backslash Y, 79\end{array}$ & iv & $\begin{array}{l}\% \circ \wedge \wedge, 0 \\
\% \wedge \vee, r)\end{array}$ & $11 \mathrm{~V}$ & أقل من فدان & 1 \\
\hline$\% \backslash r$ & $r \varepsilon$ & $\begin{array}{c}\% 1,0 \\
\% \backslash,, 0\end{array}$ & $r$ & $\begin{array}{l}\% 1 \cdot, 0 \\
\% \wedge \vee, 0\end{array}$ & Y & فدان & r \\
\hline$\% Y_{1}$ & $\varepsilon r$ & $\begin{array}{c}\% \cdot, 0 \\
\% r, r \wedge\end{array}$ & 1 & $\begin{array}{l}\text { \%r.,o } \\
\% q v, 7 r\end{array}$ & $\varepsilon 1$ & أكثر من فدان & r \\
\hline$\% 1 \ldots$ & $r \ldots$ & $\% 1 \cdot, 0$ & TI & $\% \wedge 9,0$ & 189 & الإجمالى & \\
\hline
\end{tabular}

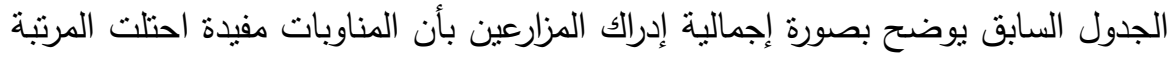

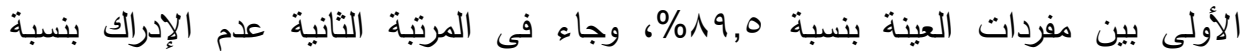

المحور الثانى: سلوكيات واتجاهات المزارعين نحو الرى فى مصر وأثره على شح المياه. جلول رقم(ب): يوضح العلاقة بين المستوى التعليمى وبين إدراك وإتجاهات المزارعين عن الرى

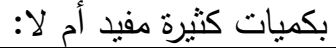

\begin{tabular}{|c|c|c|c|c|c|c|c|}
\hline النسبة & ألجمارلى & \multicolumn{2}{|l|}{ V } & \multicolumn{2}{|c|}{ نعم } & \multirow[t]{2}{*}{ الحالة التعليمية } & \multirow{2}{*}{ p } \\
\hline$\%$ & ك & $\%$ & ك5 & $\%$ & ك5 & & \\
\hline$\%$ \%r & $7 \varepsilon$ & $\begin{array}{c}\% \text { \% } \\
\% 10,74 \\
\end{array}$ & 1. & $\begin{array}{l}\% \text { \%Y } \\
\% \wedge \varepsilon, \text { }\end{array}$ & $0 \leqslant$ & أمى & 1 \\
\hline$\%$ \% & VY & $\begin{array}{l}\% 1 \cdot, 0 \\
\% \curlyvee q, i \vee\end{array}$ & Y) & $\begin{array}{l}\% \text { \% } 0,0 \\
\% \vee \cdot \lambda r\end{array}$ & 01 & يقرأ ويكتب & r \\
\hline$\% 0$ & 1. & $\begin{array}{c}\% r \\
\% \varepsilon .\end{array}$ & $\varepsilon$ & $\begin{array}{c}\% r \\
\% ч\end{array}$ & 7 & حاصل علي شهادة & r \\
\hline$\% 7,0$ & 11 & $\begin{array}{c}\% 00 \\
\% \vee 7,9 Y\end{array}$ & 1. & $\begin{array}{c}\% 1,0 \\
\% \text { \%r,.人 }\end{array}$ & $r$ & حاصل على الإعدادية & $\varepsilon$ \\
\hline$\%$ & rY & $\begin{array}{c}\% \curlyvee, 0 \\
\% \wedge \cdot, \vee \vee\end{array}$ & YI & $\begin{array}{c}\% 7,0 \\
\% 19,4,4\end{array}$ & 0 & حاصل على الثانوية أو & 0 \\
\hline$\% \varepsilon$ & $\Lambda$ & $\begin{array}{c}\% \varepsilon \\
\% 1 \ldots\end{array}$ & $\wedge$ & $\%$ & . & حاصل على مؤهل فوق & 7 \\
\hline$\%$ \%,० & V & $\begin{array}{l}\% \text { \%r,o } \\
\% 1 . .\end{array}$ & V & $\%$ & • & حاصل على مؤهل & V \\
\hline$\% 1 \ldots$ & r.. & $\% \varepsilon \cdot, 0$ & $\Lambda 1$ & $\% 09,0$ & 119 & الإجـمالك & \\
\hline
\end{tabular}


الجدول السابق يوضح بصورة إجمالية أن نسبة من يدركون أن الرى بكميات كثيرة مفيد

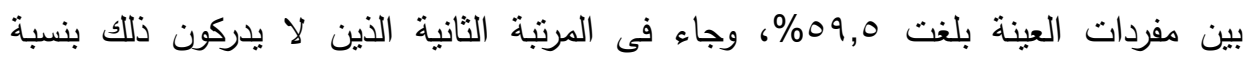
.\% • •, ० جدول رقم(ء) ): يوضح العلاقة بين الحيازة الزراعية وسلوكيات واتجاهات المزارعين خلال فترة

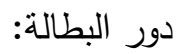

\begin{tabular}{|c|c|c|c|c|c|c|c|c|c|}
\hline \multirow{2}{*}{ النسبة } & \multirow{2}{*}{ ألتكرالى } & \multicolumn{2}{|c|}{ الري منية. المياه } & \multicolumn{2}{|c|}{ البوابات بقتح أرضى } & \multicolumn{2}{|c|}{ يروى من مياه } & \multirow[t]{2}{*}{ المزيعية } & \\
\hline & & $\%$ & 5 & $\%$ & 5 & $\%$ & ك & & \\
\hline \%тV & $1 \pi \varepsilon$ & $\begin{array}{l}\text { \%ro } \\
\% \text { \% Y,Y }\end{array}$ & $v$. & $\begin{array}{c}\% 0 \\
\% \vee, \leq 7\end{array}$ & 1. & $\begin{array}{c}\% \text { \%Y } \\
\% \varepsilon \cdot, r .\end{array}$ & $0 \leqslant$ & & \\
\hline$\% \backslash r$ & $Y \varepsilon$ & $\begin{array}{c}\text { \%q } \\
\% \vee 0\end{array}$ & 11 & $\begin{array}{l}\% \cdot, 0 \\
\% \varepsilon, i \vee\end{array}$ & 1 & $\begin{array}{c}\% \text { \%r,o } \\
\% r \cdot, \lambda r\end{array}$ & 0 & فدان & \\
\hline$\%$ rl & $\varepsilon r$ & $\begin{array}{c}\% \% 0 \\
\% r+, \wedge)\end{array}$ & 1. & . & - & $\begin{array}{c}\% 17 \\
\% \vee 4,19\end{array}$ & Tr & أكثر من فدان & $r$ \\
\hline$\% 1 \ldots$ & T.. & $\% \leqslant 9$ & 91 & $\% 0,0$ & 11 & $\% \leqslant 0,0$ & 91 & الإجـــالي & \\
\hline
\end{tabular}

الجدول السابق يوضح بصورة إجمالية أن الرى من المياه الجوفية إحتل المرنبة الأولى بين

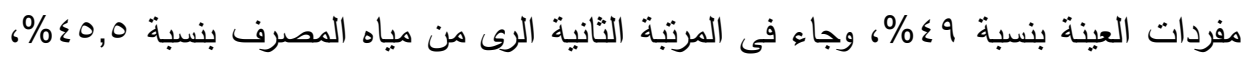

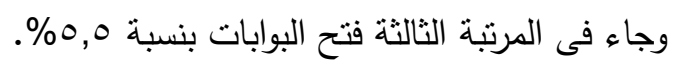


يتناول الفصل الخامس تحت عنوان: مظاهر البيئة الطبيعية (الفيزيقية) وتأثيرها على شح المياه، من خلال المحور الثالث: أثز البيئة الطبيعية (الفيزيقية) على شح المياه. جدول رقم(ه): يوضح العلاقة بين المستوى التعليمى وبين اختبار مواعيد الرى:

\begin{tabular}{|c|c|c|c|c|c|c|c|c|c|}
\hline النسبة & ألتكرارل & \multicolumn{2}{|c|}{ بالليل. } & \multicolumn{2}{|c|}{ فَى ألى وقت } & \multicolumn{2}{|c|}{ الصبح بلرى قبل } & \multirow{2}{*}{ التعليمية } & \\
\hline$\%$ & ك & $\%$ & ك & $\%$ & ك) & $\%$ & 5 & & \\
\hline$\%$ \%r & $7 \varepsilon$ & $\begin{array}{c}\% \text { \% , } \\
\% 1 \cdot, 9 \leq\end{array}$ & V & $\begin{array}{c}\% \% ! \\
\% r, 1\}\end{array}$ & r & $\begin{array}{l}\% Y \vee, 0 \\
\% \wedge \text { Q } 9 \leq\end{array}$ & 00 & & \\
\hline \%r & VY & $\begin{array}{c}\% \circ \\
\% ॥, \wedge 9\end{array}$ & 1. & $\begin{array}{l}\% 1,0 \\
\% \varepsilon, i \vee\end{array}$ & r & $\begin{array}{l}\% \text { \% q,0 } \\
\% \wedge 1, q \leq\end{array}$ & 09 & يقرأ ويكتب & T \\
\hline$\% 0$ & 1. & $\begin{array}{l}\% 1,0 \\
\% \text { r. }\end{array}$ & r & $\begin{array}{l}\% \cdot, 0 \\
\% 1 .\end{array}$ & 1 & $\begin{array}{l}\% r \\
\% \uparrow .\end{array}$ & 7 & شاصل عادة الابتدائية & $\mu$ \\
\hline$\% 7,0$ & $\pi$ & $\begin{array}{l}\% \leqslant, 0 \\
\% \neg 9, r \text { r }\end{array}$ & 9 & $\%$. & - & $\begin{array}{c}\% \% r \\
\% r \cdot, V V\end{array}$ & $\varepsilon$ & حاصل على الإعدية & \\
\hline \%) & r & $\begin{array}{l}\% 1 \text {. } \\
\% \vee 7, q 4\end{array}$ & $r$. & $\%$. & - & $\begin{array}{c}\% r \\
\% r r, \cdot \wedge\end{array}$ & 1 & دالثانوية أولى & 0 \\
\hline$\% \varepsilon$ & $\wedge$ & $\begin{array}{l}\% \curlyvee, 0 \\
\% \wedge \vee, ०\end{array}$ & V & $\%$. & - & $\begin{array}{l}\% \cdot, 0 \\
i r, 0\end{array}$ & 1 & مؤهل فوقل على من & 1 \\
\hline$\%$ \%,० & V & $\begin{array}{l}\% \%, 0 \\
\% 1 . .\end{array}$ & V & $\%$. & - & $\%$. & . & مؤهل جاصل & v \\
\hline$\% 1 \ldots$ & r.. & $\% \Psi_{1,0}$ & $7 \pi$ & $\% \pi$ & 7 & $\% 70,0$ & $1 \pi$ & الإجمالى ع & \\
\hline
\end{tabular}

الجدول السابق يوضح بصورة إجمالية أن موعد الرى فى الصبح بدرى قبل طلوع الثمس

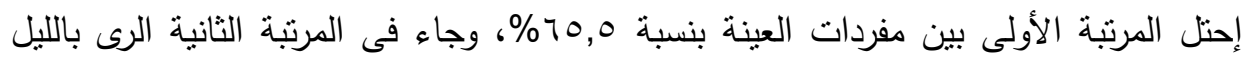

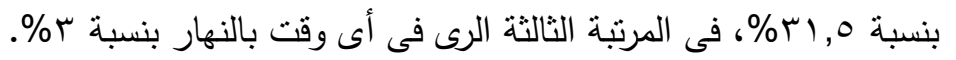


جدول رقم(7): يوضح العلاقة بين المستوى التعليمى وبين طريقة تسوية الأرض الزراعية:

\begin{tabular}{|c|c|c|c|c|c|c|c|}
\hline النسبة & ألتكرالى & 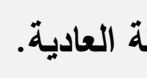 & 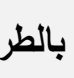 & الليزر & & a & م \\
\hline$\%$ & s & $\%$ & ك & $\%$ & ك & & \\
\hline$\%$ \%r & $7 \varepsilon$ & $\begin{array}{c}\% \text { \%ry } \\
\% \wedge \lambda, \text {, }\end{array}$ & Or & $\begin{array}{c}\% \uparrow \uparrow \\
\% \backslash \wedge, \vee \circ\end{array}$ & Ir & أمى & 1 \\
\hline \%нч & $V Y$ & $\begin{array}{l}\text { \%rV,o } \\
\% \vee \neg, r q\end{array}$ & 00 & $\begin{array}{l}\% \uparrow \wedge, 0 \\
\% \curlyvee r, \uparrow 1\end{array}$ & IV & يقرأ ويكتب & r \\
\hline$\% 0$ & 1. & $\begin{array}{l}\% Y, 0 \\
\% ० \text {. }\end{array}$ & 0 & $\begin{array}{l}\% \text { \% , } \\
\% ० \text {. }\end{array}$ & 0 & حاصل علي شهادة & r \\
\hline$\% \curlyvee, 0$ & $1 \pi$ & $\begin{array}{c}\% r \\
\% \leqslant 7,10\end{array}$ & 7 & 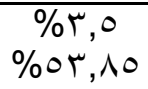 & V & حاصل على الإعدادية & $\varepsilon$ \\
\hline$\%$ & Y & $\begin{array}{c}\% 0,0 \\
\% \leqslant r, r)\end{array}$ & 11 & $\begin{array}{l}\% \vee \vee 0 \\
\% \vee 0,79\end{array}$ & 10 & حاصل على الثانوية آو & 0 \\
\hline$\% \varepsilon$ & $\wedge$ & $\begin{array}{l}\% \cdot, 0 \\
\% \backslash r, 0\end{array}$ & 1 & $\begin{array}{l}\% \Psi, 0 \\
\% \wedge \vee, 0\end{array}$ & V & حاصل على مؤهل فوق & 7 \\
\hline$\%$ \%,० & V & $\%$. & . & $\begin{array}{l}\% r, 0 \\
\% 1 . .\end{array}$ & V & حاصل على مؤهل جامعى & V \\
\hline$\% 1 \ldots$ & $r \ldots$ & $\% 70$ & $\overline{T \pi}$. & $\%$ ro & V. & الإجـمالـى & \\
\hline
\end{tabular}

الجدول السابق يوضح بصورة إجمالية أن نسوية الأرض بالطريقة العادية احتلت المرتبة

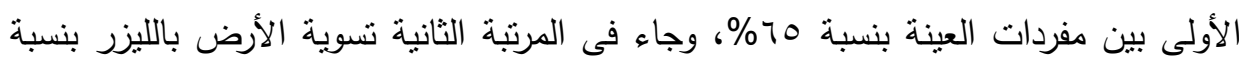
\%ro

جدول رقم(V): يوضح العلاقة بين نسبة الحيازة الزراعية وسلوكيات المزارعين نحو كيفية التخلص من القمامة والحيوانات الميتة:

\begin{tabular}{|c|c|c|c|c|c|c|c|}
\hline \multirow{2}{*}{ النسبة } & \multirow{2}{*}{ ألتكرالى } & \multicolumn{2}{|c|}{ 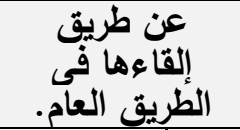 } & \multicolumn{2}{|c|}{ بالمجاريى المائية. } & \multirow[t]{2}{*}{ الحيازة المزرعية } & \multirow[t]{2}{*}{ r } \\
\hline & & $\%$ & ك & $\%$ & S & & \\
\hline \%тV & $1 \pi \varepsilon$ & $\begin{array}{l}\% \backslash 7,0 \\
\% r \varepsilon, 7 r\end{array}$ & r & $\begin{array}{l}\% 0 \cdot, 0 \\
\% \vee 0, r v\end{array}$ & $1 \cdot 1$ & أقل من فدان & 1 \\
\hline$\% \backslash r$ & $T \varepsilon$ & $\begin{array}{c}\% r, 0 \\
\% \text { \%, IV }\end{array}$ & V & 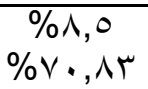 & IV & فدان & r \\
\hline$\% r_{1}$ & $\varepsilon r$ & $\begin{array}{c}\% 7,0 \\
\% r \cdot, 90\end{array}$ & M & $\begin{array}{l}\%) \leqslant, 0 \\
\% 79, .0\end{array}$ & rq & أكثر من فدان & r \\
\hline$\% 1 \ldots$ & r... & $\%$ \%४ ,० & or & $\% \vee r, 0$ & $1 \leqslant V$ & الإجـــالم & \\
\hline
\end{tabular}


الجدول السابق يوضح بصورة إجمالية أن طريقة تخلص المزارعين من القمامة والحيوانات

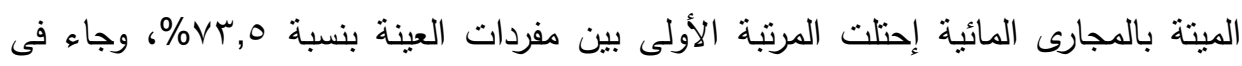

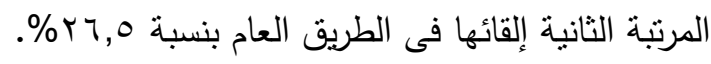
جدول رقم(^): يوضح العلاقة بين نسبة الحيازة الزراعية وبين طريقة تسوية الأرض الزراعية:

\begin{tabular}{|c|c|c|c|c|c|c|c|}
\hline النسبة & ألتكمارلى & \multicolumn{2}{|c|}{ بالطريقة العادية. } & \multicolumn{2}{|c|}{ بالليزر } & \multirow{2}{*}{ الحيازة المزرعية } & \multirow{2}{*}{ r } \\
\hline$\%$ & ك & $\%$ & ك & $\%$ & ك & & \\
\hline$\% 7 V$ & 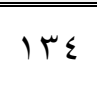 & $\begin{array}{c}\% \% \diamond \wedge \\
\% \wedge 7,0 \vee\end{array}$ & 117 & $\begin{array}{c}\% q \\
\% \mid r, \varepsilon r\end{array}$ & 11 & أقل من فدان & 1 \\
\hline$\% 1 r$ & $Y \varepsilon$ & $\begin{array}{l}\% \text { \%r } \\
\% \text { ro }\end{array}$ & 7 & $\begin{array}{l}\% q \\
\% \vee 0\end{array}$ & 11 & فدان & r \\
\hline$\%$ \% & $\varepsilon r$ & $\begin{array}{c}\% \leq \\
\% \backslash 9, .0\end{array}$ & $\wedge$ & $\begin{array}{c}\% \backslash \vee \\
\% \wedge \cdot, 90\end{array}$ & rs & أكثر من فدان & r \\
\hline$\% 1 \ldots$ & r.. & $\%$ \%० & $\pi$ & $\%$ \%० & $V$. & الإجماللي & \\
\hline
\end{tabular}

الجدول السابق يوضح بصورة إجمالية أن تسوية الأرض بالطريقة العادية إحتلت المرتبة

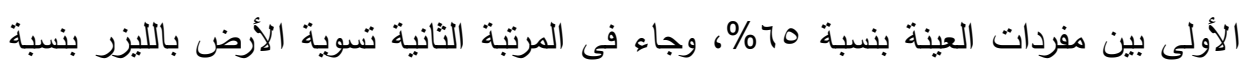
\%ro

يتتاول الفصل الساد تحت عنوان: شح المياه وأثره على المزارعين والأراضى الزراعية، من خلال المحور الرابع: أثر شح المياه على المزارعين والأراضى الزراعية. 
جدول رقم(9): يوضح العلاقة بين المستوى التعليمى وما يحدث بين المزارعين عند انخفاض المياه فى الترعة:

\begin{tabular}{|c|c|c|c|c|c|c|c|}
\hline \multirow{2}{*}{ النسبة } & \multirow{2}{*}{ أجمالى } & \multicolumn{2}{|c|}{ تعاون الإيجاد وسيلةً } & \multicolumn{2}{|c|}{ المزارعين على الرين } & \multirow[t]{2}{*}{ الحالة التعليمية } & \multirow[t]{2}{*}{ ? } \\
\hline & & $\%$ & 5 & $\%$ & ك5 & & \\
\hline \%rr & $7 \varepsilon$ & 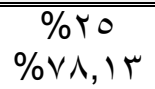 & 0. & $\begin{array}{c}\% \vee \\
\% \curlyvee), \wedge v\end{array}$ & $1 \varepsilon$ & 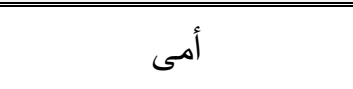 & 1 \\
\hline \%нт & VY & 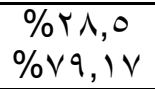 & or & $\begin{array}{c}\% \vee, 0 \\
\% r \cdot, \lambda r\end{array}$ & 10 & يقرأ ويكتب & r \\
\hline$\% 0$ & 1. & $\begin{array}{c}\% \varepsilon \\
\% \wedge\end{array}$ & $\wedge$ & $\begin{array}{c}\% \text { \% } \\
\% \text { Y. }\end{array}$ & r & حاصل علي شُائية & r \\
\hline$\% \uparrow, 0$ & Tr & $\begin{array}{c}\% 0,0 \\
\% \wedge \varepsilon, 7 Y\end{array}$ & 11 & $\begin{array}{c}\% \text { \%) } \\
\% \backslash 0, \Gamma \wedge\end{array}$ & r & حاصل على الإعدادية & $\varepsilon$ \\
\hline$\%$ & ry & $\begin{array}{c}\% \backslash 1 ! \\
\% \wedge \varepsilon, 7 Y\end{array}$ & YY & $\begin{array}{c}\% r \\
\% \backslash 0, r \wedge\end{array}$ & $\varepsilon$ & حاصل على الثانوية آو & 0 \\
\hline$\% \varepsilon$ & $\wedge$ & $\begin{array}{l}\% \curlyvee, 0 \\
\% \wedge \vee, 0\end{array}$ & V & $\begin{array}{l}\% \cdot, 0 \\
\% \backslash r, 0\end{array}$ & 1 & حاصل على مؤهل فوق & 7 \\
\hline$\%$ \%,० & v & $\begin{array}{l}\% r, 0 \\
\% 1 \ldots\end{array}$ & v & $\%$. & . & حاصل على مؤهل جامعى & $\checkmark$ \\
\hline$\% 1 \ldots$ & $r \ldots$ & $\% \wedge 1$ & 174 & $\% 19$ & rᄉ & الإج & \\
\hline
\end{tabular}

الجدول السابق يوضح بصورة إجمالية أن تعاون المزارعين مع بعض لإيجاد وسيلة للرى

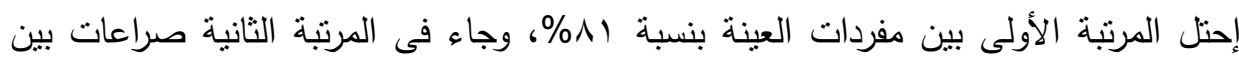

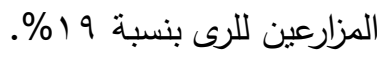


يتناول الفصل السابع تحت عنوان: التكيف ومواجهة شح المباه، من خلال المحور الخامس: سبل التكيف ومواجهة شح المياه والمشكلات الناتجة عنه والحد منها. جدول رقم( • 1): يوضح العلاقة بين المستوى التعليمى وما يفعله المزارعون عند عدم وجود مياه فى التزعة

\begin{tabular}{|c|c|c|c|c|c|c|c|c|c|}
\hline \multirow{2}{*}{ النسبة } & \multirow{2}{*}{ ألتكرار } & \multicolumn{2}{|c|}{ مياه الصري من } & \multicolumn{2}{|c|}{ الصرفي الزراعيى مناه } & \multicolumn{2}{|c|}{ بتروي منية المياه } & \multirow[t]{2}{*}{ التعليمية } & \\
\hline & & $\%$ & ك5 & $\%$ & ك5 & $\%$ & ك & & \\
\hline \%rr & $7 \varepsilon$ & $\begin{array}{l}\% r, 0 \\
\% \vee, \wedge\end{array}$ & 0 & $\begin{array}{c}\% r, 0 \\
\% 1 \cdot, 9 \leq\end{array}$ & V & $\begin{array}{c}\% \text { \%YY } \\
\% \wedge \lambda, \text {, }\end{array}$ & or & أمى & 1 \\
\hline$\%$ \%ч & VY & $\begin{array}{c}\% \text { \% } \\
\% \text { \%, } \vee \wedge\end{array}$ & r & $\begin{array}{l}\% \curlyvee, 0 \\
\% \curlyvee, 9 \leq\end{array}$ & 0 & $\begin{array}{l}\% r r, 0 \\
\% 9 \cdot, r \wedge\end{array}$ & 70 & يقرأ ويكتب & \\
\hline$\% 0$ & 1 . & $\begin{array}{l}\% \text {. } \\
\% \text {. }\end{array}$ & - & $\begin{array}{l}\% 1,0 \\
\% \text { r. }\end{array}$ & r & $\begin{array}{l}\% r, 0 \\
\% \vee .\end{array}$ & v & شاصل عادة الابتد & T \\
\hline$\% \curlyvee, 0$ & 14 & $\%$. & - & $\begin{array}{c}\% 1,0 \\
\% \text { rr, }, \Lambda\end{array}$ & r & $\begin{array}{c}\% 0 \\
\% \vee 7,94\end{array}$ & 1 . & الإعدادية على & \\
\hline$\%$ & r & $\%$. & - & $\begin{array}{l}\% \cdot, 0 \\
\% \text { \%, }\end{array}$ & 1 & $\begin{array}{l}\% \backslash r, 0 \\
\% 97,10\end{array}$ & ro & دالثانوية أولى ديلى & \\
\hline$\% \varepsilon$ & $\wedge$ & $\%$. & - & $\begin{array}{l}\% 1 \\
\% \text { ro }\end{array}$ & r & $\begin{array}{l}\% r \\
\% \vee 0\end{array}$ & 7 & مأهل فوق على ماصن & 7 \\
\hline$\%$ \%,० & V & $\%$. & - & $\begin{array}{c}\% \cdot, 0 \\
\% 1 \leq,, Y q\end{array}$ & 1 & $\begin{array}{c}\% r \\
\% \wedge 0, \vee \backslash\end{array}$ & 7 & مؤهل جامعل على & $V$ \\
\hline$\% 1 \ldots$ & r... & $\%$ \% ,० & $\mathrm{V}$ & $\% 11$ & YY & $\% \wedge \bullet, 0$ & $1 \mathrm{VI}$ & الإجــــــــ & \\
\hline
\end{tabular}

الجدول السابق يوضح بصورة إجمالية أن القيام بالرى من المياه الجوفية إحتل المرتبة الأولى بين مفردات العينة بنسبة 10,0\%، وجاء في المرتبة الثنانية قيام المزارعين بالرى من مياه

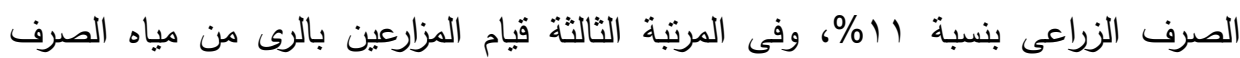

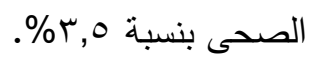


جدول رقم(1) 11 ) يوضح العلاقة بين المستوى التعليمى وما يفعله المزارعون عند حدوث مشاكل فى الرى

\begin{tabular}{|c|c|c|c|c|c|c|c|c|c|}
\hline \multirow{2}{*}{ النسبة } & \multirow{2}{*}{ ألتكمارى } & \multicolumn{2}{|c|}{ 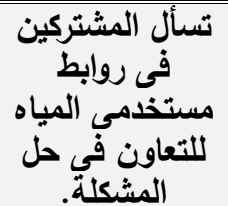 } & \multicolumn{2}{|c|}{ 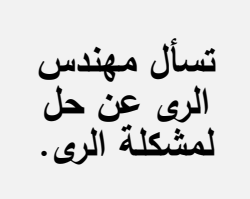 } & \multicolumn{2}{|c|}{ لوزلرة شكاوى الرى } & \multirow[t]{2}{*}{ التعليمية } & \\
\hline & & $\%$ & ك & $\%$ & ك5 & $\%$ & ك & & \\
\hline$\% r r$ & $7 \varepsilon$ & $\begin{array}{c}\% \vee V \\
\% \curlyvee ।, \wedge \wedge\end{array}$ & $1 \varepsilon$ & $\begin{array}{c}\% \text { \% } \\
\% \vee \wedge, I Y\end{array}$ & 0 . & $\%$. & . & & \\
\hline \%тr & VY & $\begin{array}{c}\% 10 \\
\% \leqslant 1,7 \vee\end{array}$ & $r$. & $\begin{array}{c}\text { \%रr } \\
\% \circ \wedge, r \text { r }\end{array}$ & $\varepsilon r$ & $\%$. & . & يقرأ ويكتب & \\
\hline$\% 0$ & 1. & $\begin{array}{l}\% l \\
\% r .\end{array}$ & $r$ & $\begin{array}{c}\% \varepsilon \\
\% \wedge .\end{array}$ & $\wedge$ & $\%$. & • & عالإيت شيادية & \\
\hline$\% \curlyvee, 0$ & $1 \pi$ & 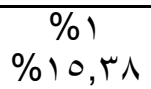 & $r$ & $\begin{array}{c}\% \odot 0,0 \\
\% \wedge \varepsilon, 7\}\end{array}$ & 11 & $\%$. & . & حاصل على الإعدادية & \\
\hline$\%$ & $r q$ & $\begin{array}{c}\% r \\
\% r r, \cdot \wedge\end{array}$ & 7 & $\begin{array}{c}\% 1 . \\
\% \vee 7, q 4\end{array}$ & $r \cdot$ & $\%$. & • & 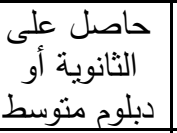 & \\
\hline$\% 乞$ & $\wedge$ & $\%$. & . & $\begin{array}{l}\% r, 0 \\
\% r r, 0\end{array}$ & 0 & $\begin{array}{l}\% 1,0 \\
\% r v, 0\end{array}$ & $r$ & مأهل فوق على ماصل & 7 \\
\hline$\%$ \%,० & v & $\%$. & . & $\begin{array}{c}\% 〉 \\
\% \curlyvee \wedge, 0 \vee\end{array}$ & r & $\begin{array}{c}\% r, 0 \\
\% \vee 1, \varepsilon r\end{array}$ & 0 & & V \\
\hline$\% 1 \ldots$ & $r \ldots$ & \%rV & $0 \leqslant$ & $\% 79$ & $1 \pi \Lambda$ & $\% \leq$ & $\Lambda$ & الإجمالي & \\
\hline
\end{tabular}

الجدول السابق يوضح بصورة إجمالية أن قيام المزارعين بسؤال مهندس الرى لحل المشكلة

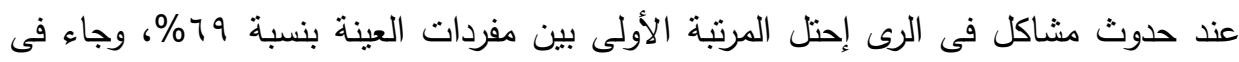

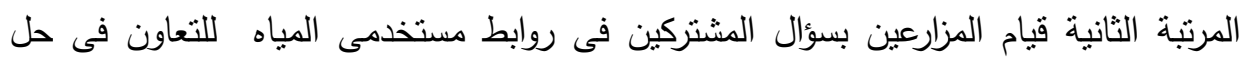

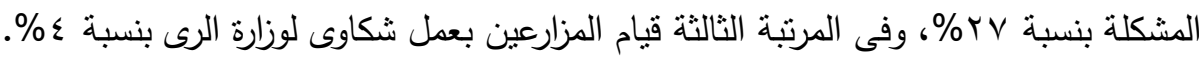


جدول رقم(r ا ): يوضح العلاقة بين نسب الحيازة الزراعية وما يفعله المزارعون عند انخفاض المياه فى التزعة

\begin{tabular}{|c|c|c|c|c|c|c|c|c|c|c|c|}
\hline \multirow{2}{*}{$\begin{array}{l}\text { النسبة } \\
\% \\
\end{array}$} & \multirow[t]{2}{*}{ 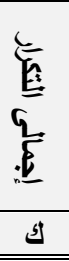 } & \multicolumn{2}{|c|}{ الرى من المياه } & \multicolumn{2}{|c|}{ تزتاج محاصيل كمية لا كبيرة } & \multicolumn{2}{|c|}{ 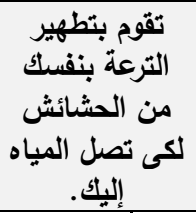 } & \multicolumn{2}{|c|}{ ماكينة رفع للتمياه. } & \multirow[t]{2}{*}{ Ẽ: } & \multirow[t]{2}{*}{ r } \\
\hline & & $\%$ & ك & $\%$ & ك5 & $\%$ & ك & $\%$ & ك & & \\
\hline \%тV & $1 T \varepsilon$ & $\begin{array}{c}\% \backslash 4 \\
\% r r, \wedge \wedge\end{array}$ & r & $\begin{array}{c}\% \vee, 0 \\
\% 11,19\end{array}$ & 10 & $\begin{array}{l}\% \backslash \wedge, 0 \\
\% \curlyvee \vee, \neg \mid\end{array}$ & rV & $\begin{array}{c}\text { \%ro } \\
\% \text { וrv,ru }\end{array}$ & 0. & ف أقل & 1 \\
\hline$\% \backslash r$ & $r \varepsilon$ & $\begin{array}{c}\% \curlyvee \\
\% \backslash \backslash, T \vee\end{array}$ & $\varepsilon$ & $\begin{array}{l}\% . \\
\% .\end{array}$ & • & $\begin{array}{c}\% 1 \\
\% \wedge, r r\end{array}$ & $r$ & $\begin{array}{c}\% q \\
\% \vee 0\end{array}$ & 11 & فدان & $r$ \\
\hline$\% r_{1}$ & $\varepsilon r$ & $\begin{array}{l}\% \\
\%\end{array}$ & • & $\begin{array}{l}\% \cdot, 0 \\
\% \curlyvee, \text {, }\end{array}$ & 1 & $\begin{array}{l}\% \cdot, 0 \\
\% \curlyvee, \text {, }\end{array}$ & 1 & $\begin{array}{c}\% r . \\
\% 90, r \leq\end{array}$ & $\varepsilon$. & ف & $r$ \\
\hline$\% 1 \ldots$ & $r \ldots$ & $\% \backslash \wedge$ & r & $\% \wedge$ & 17 & $\% r$. & $\varepsilon$. & $\% \circ \leq$ & 1.1 & الىى & \\
\hline
\end{tabular}

الجدول السابق يوضح بصورة إجمالية أن القيام بتركيب ماكينة لرفع المياه احتل المرتبة

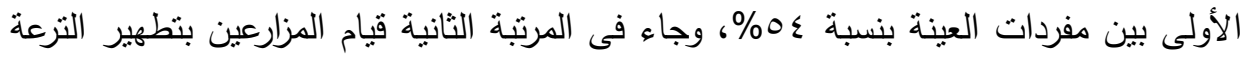

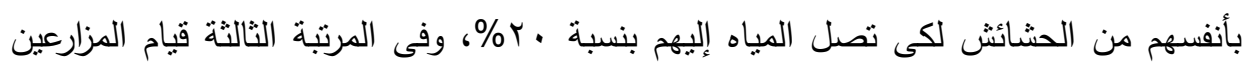

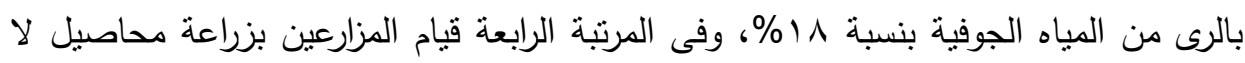

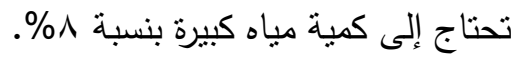

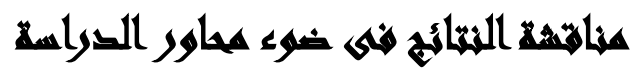

المحور الأول: المستوى المعرفى والثقافى للمزارعين بالوضع المائى فى مصر وأثره على شتح المياه. ( العلاقة بين المستوى التعليمى ومعرفة نوعية مشاكل المياه فى مصر

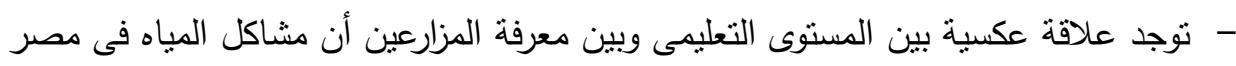
تكمن فى الكمية فقط. 
- توجد علاقة طردية بين المستوى التعليمى وبين معرفة المزارعين أن مشاكل المياه فى مصر

$$
\text { تكمن فى الكمية والنوعية. }
$$

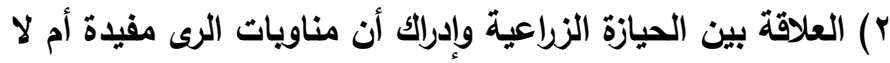
- توجد علاقة طردية بين الحيازة الزراعية وبين إدراك أن مناوبات الرى مفيدة.

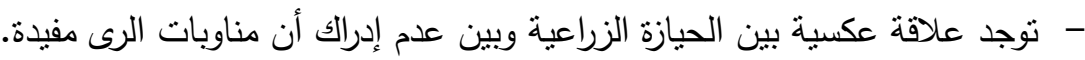
المحور الثانى: سلوكيات واتجاهات المزارعين نحو الرى فى مصر وأثره على شح المياه. 1) العلاقة بين المستوى التعليمى ويبن إدراك وإتجاهات المزارعين عن الرى بكميات كثيرة مفيد أم لا

- توجد علاقة عكسية بين الحالة التعليمية وبين إدراك وإتجاهات المزارعين أن الرى بكميات كثيرة مفيد.

- توجد علاقة طردية بين الحالة التعليمية وبين إدراك وإتجاهات المزارعين أن الرى بكميات كثيرة غير مفيد.

r) العلاقة بين الحيازة الزراعية وسلوكيات واتجاهات المزارعين خلال فترة دور البطالة

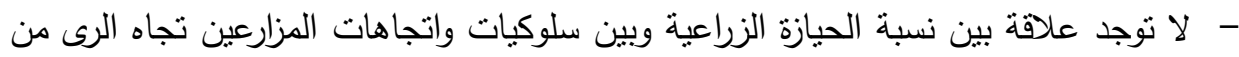
المصرف أو المياه الجوفية خلال فترة البطالة. - توجد علاقة عكسية بين نسبة الحيازة الزراعية وبين سلوكيات واتجاهات المزارعين تجاه الرى لـوليط عن طريق فتح البوابات خلال فترة البطالة. المحور الثالث: أثر البيئة الطبيعية (الفيزيقية) على شح المياه. 1) العلاقة بين المستوى التعليمى ويين اختيار مواعيد الرى - توجد علاقة عكسية بين المستوى التعليمى وبين الرى فى الصبح بدرى قبل طلوع الثمس. - لاتوجد علاقة بين المستوى التعليمى وبين الرى فى أى وقت بالنهار . - توجد علاقة طردية بين المستوى التعليمى وبين الرى بالليل. 
r) العلاقة بين المستوى التعليمى و بين طريقة تسوية الأرض الزراعية - توجد علاقة طردية بين المستوى التعليمى وبين طريقة تسوية الأرض بالليزر . - نوجد علاقة عكسية بين المستوى التعليمى وبين طريقة تسوية الأرض بالطريقة العادية.

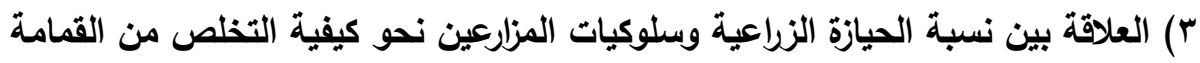
والحيوانات الميتة

- توجد علاقة عكسية بين نسبة الحيازة الزراعية وبين طريقة تخلص المزارعين من القمامة والحيوانات الميتة عن طريق إلقائها بالمجارى المائية.

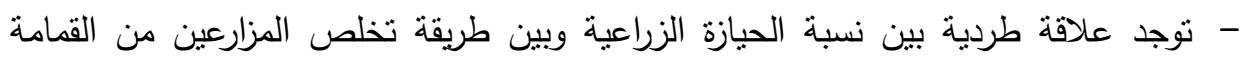
والحيوانات الميتة عن طريق إلقائها بالطريق العام.

؛) العلاقة بين نسبة الحيازة الزراعية وبين طريقة تسوية الأرض الزراعية

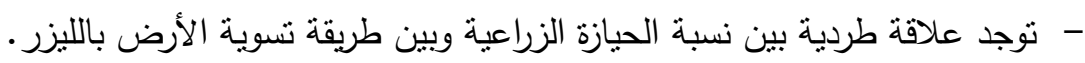
- توجد علاقة عكسية بين نسبة الحيازة الزراعية وبين طريقة نسوية الأرض بالطريقة العادية. المحور الرابع: أثر شح المياه على المزارعين والأراضى الزراعية. ( ) العلاقة بين المستوى التعليمى وما يحدث بين المزارعين عند انخفاض المياه فى الترعة - توجد علاقة عكسية بين المستوى التعليمى وما يحدث بين المزارعين من صراعات عند انخفاض المياه فى الترعة. - توجد علاقة طردية بين المستوى التعليمى وما يحدث بين المزارعين من تعاون عند انخفاض النهاه

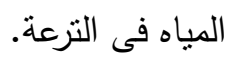

المحور الخامس: سبل التكيف ومواجهة شح المياه والمشكلات الناتجة عنه وإلحد منها ( ) العلاقة بين المستوى التعليمى وما يفعله المزارعون عند عدم وجود مياه فى الترعة - لاتوجد علاقة بين المستوى التعليمى وبين قيام المزارعين بالرى من المياه الجوفية أو مياه الصرف الزراعى عند عدم وجود المياه فى التزعة. 
- توجد علاقة عكسية بين المستوى التعليمى وبين قيام المزارعين بالرى بمياه الصرف الصحى عند عدم وجود المياه فى الترعة.

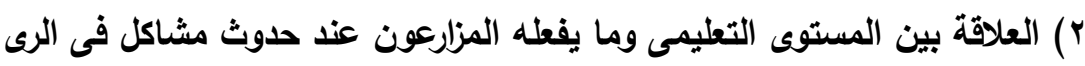

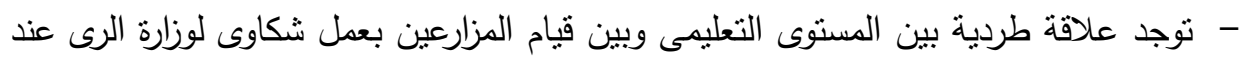
حدوث مشاكل فى الرى.

- لا توجد علاقة بين المستوى التعليمى وبين قيام المزارعين بسؤال مهندس الرى أو سؤال المشتركين فى روابط المياه عند حدوث مشاكل فى الرى.

r) العلاقة بين نسب الحيازة الزراعية وما يفعله المزارعون عند انخفاض المئن المياه فى الترعة

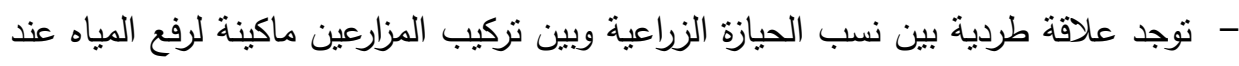
انخفاض المياه فى التزعة.

- توجد علاقة عكسية بين نسب الحيازة الزراعية وبين قيام المزارعين بتطهير الترعة بأنفسهر من الحشائش لكى تصل المياه إليهم عند انخفاض المياه فى الترعة. - لا توجد علاقة بين نسب الحيازة الزراعية وبين قيام المزارعين بزراعة محاصيل لا تحتاج إلى كمية مياه كبيرة عند انخفاض المياه فى الترعة. - نوجد علاقة عكسية بين نسب الحيازة الزراعية وبين قيام المزارعين بالرى من المياه الجوفية التئه عند انخفاض المياه فى الترعة.

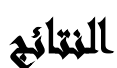

- اتضح من خلال نتائج الدراسة أن المستوى المعرفى والثقافى المتدنى للمزارعين والخاص المهاب بالمياه وترشيدها أحد الأسباب التى تنؤدى إلى شح النى المياه.

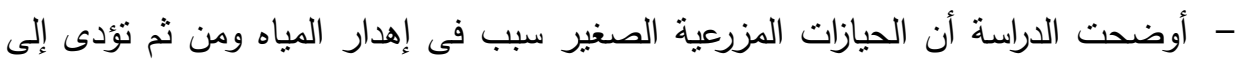
شتح المياه. 
- أكدت الدراسة أن سلوكيات واتجاهات المزارعين والخاصة بالزراعات والمحاصيل الثرهة

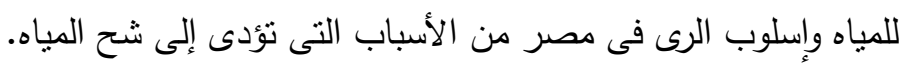
- أوضحت الدراسة أن البيئة الطبيعية (الفيزيقية) منل البنية التحتية الضعيفة وغير التئية المؤهلة، وكذلك درجات الحرارة المرتفعة الناتجة عن التغير المناخى، ومواعيد الرى فى فترات النهار

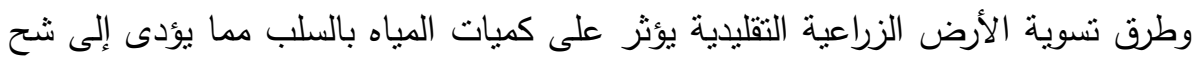
المياه. - أكدت الدراسة أن شح المياه له تأثثر بالإيجاب على المزارعين حيث يتم التعاون بينهم خلال

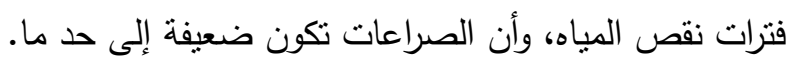
- أكدت الدراسة أن شح المياه له نأثير على المزارعين من الناحية الاقتصادية وذللك للخسارة التجارية عند هلاك المحاصيل والحيوانات المزرعية أو ضعف إنتاجيتها.

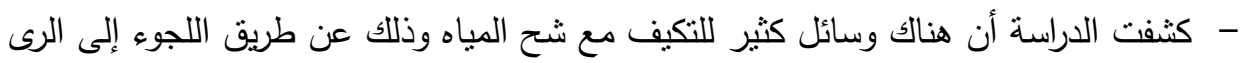
الجوفى عند إنعدام المباه فى المسقى/الترعة، أو تركيب ماكينات رفع المياه عند إنخفاض

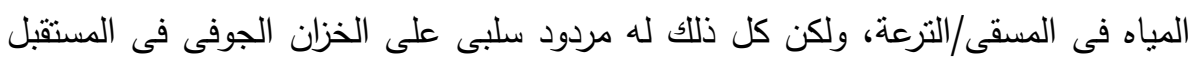
وكذلك الحالة الاقتصادية للمزارعين.

\section{الموسيايت}

من خلال النتائج التى نوصلت إليها الدراسة فيمكن أن نخرج بتوصيات للتكيف مع شح المياه ومواجهته وهى كالتالى: - عمل دورات تدريبية لرفع المستوى التقافى والمعرفى والسلوكى للمزارعين للتوعية بأهية الحفاظ على المياه والحد من التلوث بشكل دورى من خلال إدارات الإعلام بوزارتى الرى لرى والزراعة. - تحفيز المزارعين للإشترالك فى روابط مستخدمى المياه والمشاركة فى مشروع تطوير الرى، ورفع مستواهم المعرفى والمهارى وزيادة خبراتهم العملية فى مجال إدارة وصيانة ماكينات الرفع، وتغيير اتجاهاتهم للحفاظ على المياه. 
- الاستخدام الأمنل للموارد المائية للوصول إلى أكبر عائد من وحدة المياه من خلال تغليط

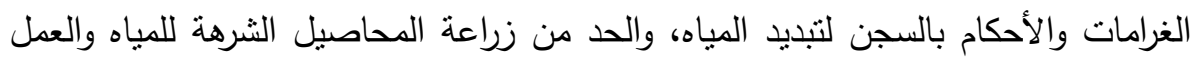
على الاستفادة من تجارة المياه الافتراضية. - تشجيع المزارعين على مشاركة المختصين بمداومة تطهير شبكة المجارى المائية من

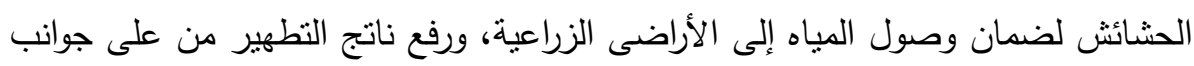
المجرى المائى.

- - إلزام المزارعين باستخدام طرق الرى المطور (رى بالرش - التقفط) للحفاظ على نقطة المياه. - بحث تركيب عدادات مياه لقياس كميات مياه الرى التى سيتم سحبها بدقة لضمان الإلنزام بالحصص المقررة. - نطوير التعليم ليواكب مفاهيم التعايش مع مشاكل شح المياه ومجالات التكنولوجيا المطلوبة للتتمية المستدامة. - بحث إدخال تقنيات تحلية المياه، واستتباط سلالات محاصيل تتحمل الجفاف والملوحة، وغير مستهلكة للمياه.

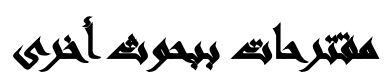

- دراسات إعلامية وثقافية عن دور الإعلام فى حملات ترشيد المياه ومواجهة التلوث. - دراسة اقتصادية عن تحلية مياه البحر وتقليل التكلفة المالية لها. - دراسة فيزيقية لاستخدامات الطاقة الثمسية فى تشغيل الآبار للتوائم مع المتغيرات المناخية.

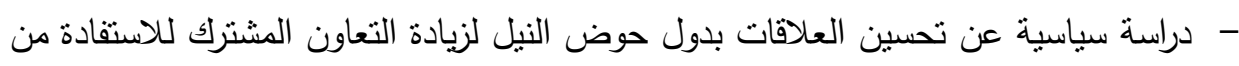

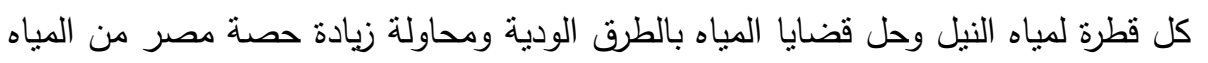
فى المستقبل القريب. 


\section{المرالية}

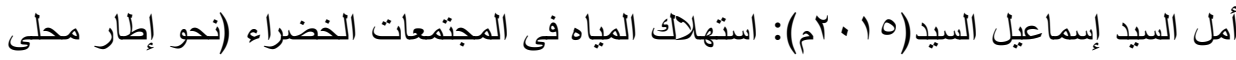
لمعايير كفاءة الاستهالك)، ماجستير، قسم التصميم العمرانى، كلية التخطيط

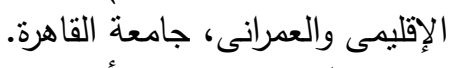

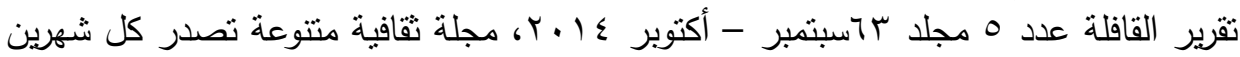
.http://qafilah.com/ar

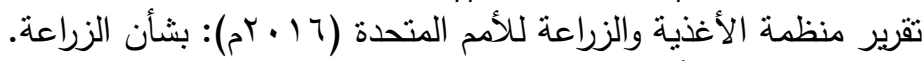

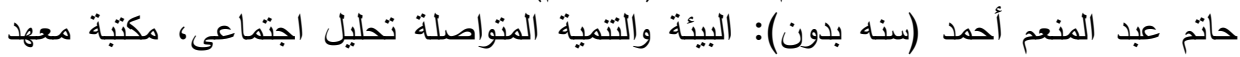
الدراسات والبحوث البيئية، القاهرة.

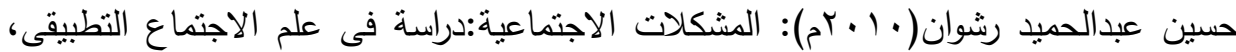

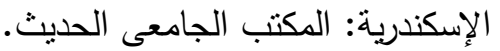

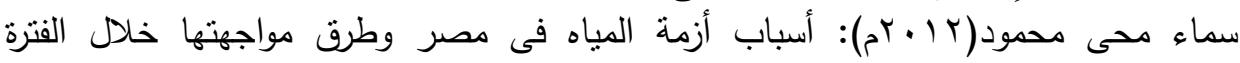

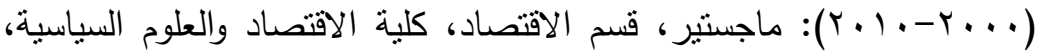

$$
\text { جامعة القاهرة. }
$$

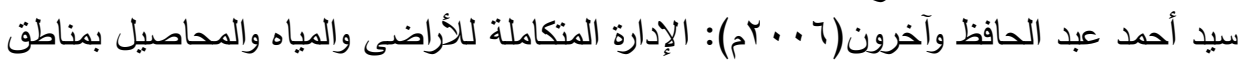
تطوير الرى، مكتبة وزارة الموارد المائية والرى، القاهرة.

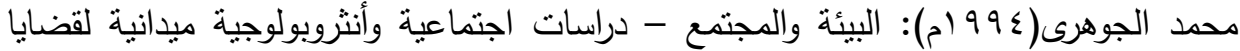
البيئة والمجتمع، الإسكندرية، دار المعائة المعرفة الجامعية.

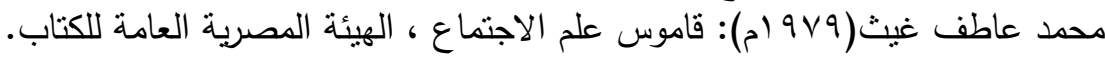

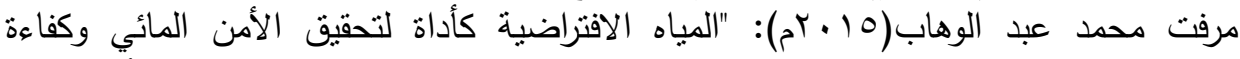

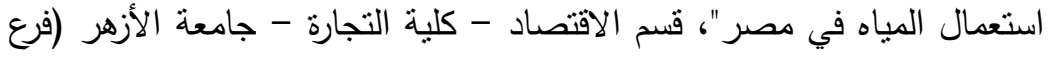

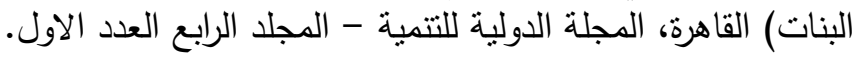
http://ar.wikipedia.org/wiki موسوعة ويكبيديات (لفيات

Basel Awni Ashour Al-Natsheh,( 2009): Soil and water management under using wastewater conditions. thesis (Ph.D.)- Faculty of Agriculture, Ain Shams University

Falkenmark. (1989): "The massive water scarcity threatening Africa why isn't it being addressed." Ambio 18, no. 2 112-118. 
Lilah Zantner (2011): A Comparative Assessment of Community Water System Vulnerability to Water Scarcity in Buckeye and Cave Creek, Arizona. thesis (master )- Arizona State university, December

Yong Xia CaI(2009): Water scarcity, Climate change, and water quality: Three Economic Essays. thesis (PhD.)- A\&M University, Texax,

\title{
SOCIAL AND PHYSICAL PROBLEMS ASSOCIATED \\ WITH WATER SCARCITY, COPING AND \\ CONFRONTATION APPROACHES \\ AN ECOLOGICAL STUDY ON SOME VILLAGES IN \\ QALUIBIA GOVERNORATE
}

Awad, M. I. ${ }^{(1)}$; El-Simary, A. M. ${ }^{(2)}$; Mohamed, H. M. ${ }^{(3)}$ and Abdel- Aal, M. S. M. S.

1) Institute of Environmental Studies \& Research, Ain Shams University

2) Faculty of Literature, Cairo University 3) The National Center for Waters Research

\begin{abstract}
This study's purpose is basically to identify the scarcity of waters and the consequent reasons in addition to the social and physical problems associated with this scarcity and the appropriate approaches to meet them. The scarcity of water problem is considered one of the most serious and critical crises threatening the future of humanity. Questions are set to identify the relationship between water scarcity and some variables, in attempt to reach a future vision for meeting the problems of water scarcity.
\end{abstract}


For fulfilling this study, some theories are applied including the ecological theory, using also the descriptive method for being the most appropriate for social researches for detecting reasons of water scarcity and the produced consequences may result in and the means farmers use to deal with.

The study also uses a questionnaire form through personal interviews to collect data; as Qalubyia governorate is selected to be the location of applying the study, for being one of the biggest Delta governorates suffering from water irrigation problems. Banha and El-Khanka centers are selected to be the study sample, which are selected randomly from (200) farmers.

\section{The study concludes to several results as follows:}

- There is a significant relationship between scarcity of waters and the social and physical problems farmers encounter, as water scarcity affects the agricultural lands either by destruction of crops or deterioration of quality of lands, leading in turn to deterioration of the farmers' economic level.

- Disposing wastes in water (such as dead animals) pollutes water and waste fresh pure waters.

- Most farmers can quickly cope with scarcity of waters through for example renting irrigation machines or irrigation through the underground waters, or through using mixed resources of waters, or by cleaning the runways and streams to let waters pass easily.

- The physical nature such as the infrastructure is so weak and unqualified, added to that the high rate of temperature, climate change, and irrigation timing are all factors affect negatively use of waters.

- Lack of programs is one of the reasons leading to poor awareness towards importance of water and its rationalization.

- The study results demonstrate that scarcity of waters affects negatively the economic sector by being exposed to commercial loss because of poor production, corruption of crops, and death of animals.

- Results indicate that penalties and fines affect positively by conserving waters.

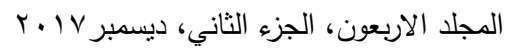




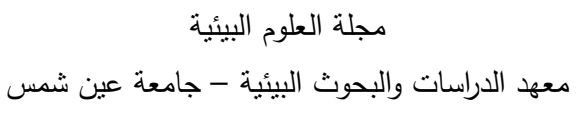

\section{The study recommends the following:}

- Holding training courses by Ministry of Irrigation and Ministry of Agriculture for farmers to elevate their cultural, cognitive, and behavioral level to conserve waters.

- Encouraging farmers to participate in waters' users associations and in developing irrigation projects.

- The optimal use of aquatic resources and magnifying fines and exposure to imprisonment for wasting waters.

- Working on covering canals and waterways inside resident blocks not to cause pollution.

- Applying rules and laws concerning restricting cultivation of crops that require lots of waters such as rice, sugarcane, and banana.

- Obligating farmers in new lands to use advanced irrigation methods such as (Sprinkler Irrigation - drip irrigation) to conserve water. 